\title{
EXPERIMENTS ON THE METERING OF LARGE VOLUMES OF AIR
}

\author{
By Howard S. Bean, M. E. Benesh, ${ }^{1}$ and Edgar Buckingham
}

ABSTRACT

The investigation comprised the following three kinds of experiment:

(a) Experiments on the flow of air from a large gas holder through a rotary displacement gas meter of 200,000 cubic feet per hour rated capacity, a 24 by 12 inch Venturi meter, and various thin-plate orifices installed in a smooth 24-inch pipe. The rate of flow was determined from observations on the holder, which was flooded by a stream of water, to control the temperature. The average precision of a determination was better tnan \pm 0.5 per cent.

(b) Series comparisons of the orifices with the Venturi, without using the holder.

(c) Observations on the distribution of static pressure along the wall of the pipe near the orifices, at various rates of flow.

The apparatus, experimental procedure, and methods of computation are described, and tables of results are given.

The rate of flow shown by the rotary displacement meter agreed with the rate computed from observations on the holder to within about 0.5 per cent; and the discharge coefficient found for the Venturi was in good agreement with earlier published values for similar Venturis, tested with water.

When the values obtained for the discharge coefficients of the orifices were so reduced as to be comparable with the most complete and accurate published values for water, the agreement was very satisfactory.

\section{CONंTENTS}

I. Preface.

II. Preface-1roduction

III. General arrangement of the apparatus

IV. Holder

1. Measurement of the dimensions

2. Height measurements

3. Control and measurement of temperature

4. Leakage test $\ldots$

V. Orifice meter installation

1. Orifices

2. Pipe

3. Honeycombs

4. Pressure taps.....

5. Water manometers

6. Wet and dry bulb psychrometer

VI. Rotary displacement meter

VII. Venturi meter

VIII. Auxiliary instruments and operations

1. Regulation of the rate of flow

2. Barometer

3. Clock $\ldots$

4. Photographic recording 
IX. Variation of pressure along the pipe near an orifice

1. Experiments _............. 104

2. Mode of representing the results

3. Tables of results

4. Variation of pressure distribution with speed of flow

5. Variation with diameter ratio

$\mathrm{X}$ Experiments with the holder 113

1. Procedure

2. Saturation in the holder

3. Computation of the rate of flow of dry air along the line--- 116

4. Computation of the density and rate of flow of moist air at any section of the line..... 117

5. Reduction of the observations on the orifices... 119

6. Reduction of the observations on the Venturi

7. Reduction of the observations on the rotary displacement

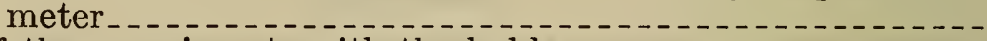

XI. Results of the experiments with the holder

1. General characteristics of the runs -

3. Results of the tests of the Venturi meter

4. Discussion of the results obtained with the Venturi

5. Discharge coefficients of the orifices_..

XII. Comparison of the orifices with the Venturi

1. Experimental procedure.

2. Computations

3. Results of the comparisons

XIII. Discussion of the results of the experiments on orifices. 130

1. Reduction for change of tap location

2. Allowance for varying density; the expansion factor

3. Witte's values of $K$ for smooth pipes

4. Comparison of the Chicago results for air with Witte's results for water

5. Conclusions from the foregoing comparison 138

6. Remarks

7. Graphical representation of Tables 16,17 , and 18

XIV. Summary

Note A-The adiabatic discharge coefficient. 143

Note B-The Reynolds number. 144

\section{PREFACE}

The investigation discussed in the following paper was initiated by the Amcrican Gas Association and was carried out, with the cooperation of the National Bureau of Standards, under the general oversight of a committee appointed by the association, on which the bureau was represented.

The work was done during the summer and autumn of 1924 at the Pitney Court Station of the Pcople's Gas Light \& Coke Co., of Chicago where a large gas holder and other important facilities were placed at the disposal of the committee. The company also furnished assistance of various kinds, and bore a large share of the cost of the operations.

The committee was indebted to the Builders Iron Foundry, of Providence, R. I., for the loan of a Venturi meter; to the Connersville Blower Co., of Connersville, Ind., for the loan of a rotary displacement meter; and to the Republic Flow Meters Co., of Chicago, Ill., for the loan, or the special construction, of numerous small but essential parts of the apparatus.

The National Bureau of Standards contributed in the matter of standardizing measuring instruments, and by advice or suggestions regarding experimental methods and the reduction of observations. 
One of the present authors (Benesh), acting as chairman of the committee, made the detailed plans for the experiments and the work was carried out under his immediate supervision. Another of the authors (Bean) represented the bureau during the experiments, and participated in them as an observer. The remaining author (Buckingham) served as a member of the committee and as an adviser in theoretical matters. $\mathrm{He}$ is responsible for the form in which the results are presented, but in preparing the paper he has received much indispensable assistance from his two colleagues.

\section{INTRODUCTION}

The main object of the undertaking was to test the accuracy of several types of meter which are in common use for measuring large quantities of gas at pressures near atmospheric. The meters in question were: (a) A series of round, square-edged orifices installed concentrically, one at a time, in a straight, smooth pipe of 24 inches nominal diameter; $(b)$ a rotary displacement meter of a rated capacity of 200,000 cubic feet per hour; and (c) a 24 by 12 inch Venturi meter.

A few tests were made on a large, wet drum, station meter, but they did not reveal anything of general interest. Observations were also made on a Thomas electric meter, but the method of operation was modified from standard commercial practice, and while the results were of interest to the makers of the meter, they might be misleading to otbers and will not be reported here.

The tests were made with air, and the large gas holder served as the absolute standard to which the other meters were referred; but in addition to the laborious and time-consuming experiments with the holder, a number of intercomparisons were made, without using the holder.

A third section of the investigation consisted in observations on the longitudinal distribution of pressure along the wall of the 24-inch pipe near the orifices. These were needed in order that the results obtained when using the orifices as meters might be compared with the published results of other observers.

The general scheme of the holder experiments was as follows: The inner lift of the holder, the only one used, was first filled with air by a centrifugal booster, warm water being sprayed into the intake to insure saturation. The connections were then changed and air was withdrawn from the holder by the booster and forced along the test line in which the meters were installed in series. From the dimensions of the holder and its rate of fall, together with observations of pressure and temperature, the mean rate of outflow of air was computed. This was then compared with the mean indications of the meters during the run and their correction factors or coefficients were thus determined with reference to the holder as the standard.

In the intercomparison tests and in the experiments on the longitudinal distribution of pressure near the orifices, the booster was disconnected from the holder and drew its air from outside.

$60869-31-7$ 


\section{GENERAL ARRANGEMENT OF THE APPARATUS}

The arrangement of the line in which the meters were installed is shown schematically in Figure 1, the notation being as follows:

$A=$ pipe leading from the holder to the booster.

$B=$ the booster.

$O=$ the pair of flanges for holding the orifice plates.

$R . D .=$ the rotary displacement meter.

$W . D .=$ the connections to the wet drum meter.

$V=$ the Venturi meter.

$T=$ a 20 -inch Thomas electric meter.

$H_{1} \ldots H_{4}=$ honeycombs.

$P_{1} \ldots P_{4}=$ wet and dry bulb psychrometers.

$t_{1}, t_{2}=$ dry bulb thermometers.

$M=$ the bank of water monometers.

Starting at the holder (off the sheet to the left), the pipe $A$ ran underground for about half its length and then up to the second floor of the meter house, where the centrifugal booster was situated. From the booster, the piping led down to the ground floor, to the entrance of the first straight section of the test line proper, containing the orifice station, the lower line in Figure 1.

By means of details not shown in the figure, provision was made for changing the connections of the booster so as to permit of: (a) Filling the holder with air from outside, $(b)$ withdrawing air from the holder and sending it along the test line through the meters, and (c) drawing air from outside and sending it directly into the test line.

The general appearance of the 41 by 90 foot first floor room may be gathered from the view in Figure 2, taken from a point near the middle of the lower edge of Figure 1. In the foreground are the water manometers and the cathetometers for reading them, and behind the manometers is the 24-inch pipe containing the orifice station. The line containing the Venturi meter was parallel to the orifice line, about 10 feet to the left and behind. The rotary displacement meter is shown in the right background. This meter could be either included in the line or by-passed, by shifting a blank plate from one flange joint to another.

The wet drum meter, which came next after the rotary displacement meter, was by-passed in all the experiments to be reported, and it is not necessary to describe the somewhat circuitous route by which the air reached the entrance to the straight pipe leading to the Venturi meter.

\section{HOLDER}

\section{MEASUREMENT OF THE DIMENSIONS}

The mean radius of the inner lift of the holder was found by the following process: The distance from a mark at the center of the crown to a punch mark on each of the 21 columns of the surrounding framework was measured with a steel tape. By means of a plumb line, a second mark was located on each column, directly below the first at a convenient height for measuring the distance from the column back to the shell, and this distance was measured. Departures of the plating from verticality were determined along each 


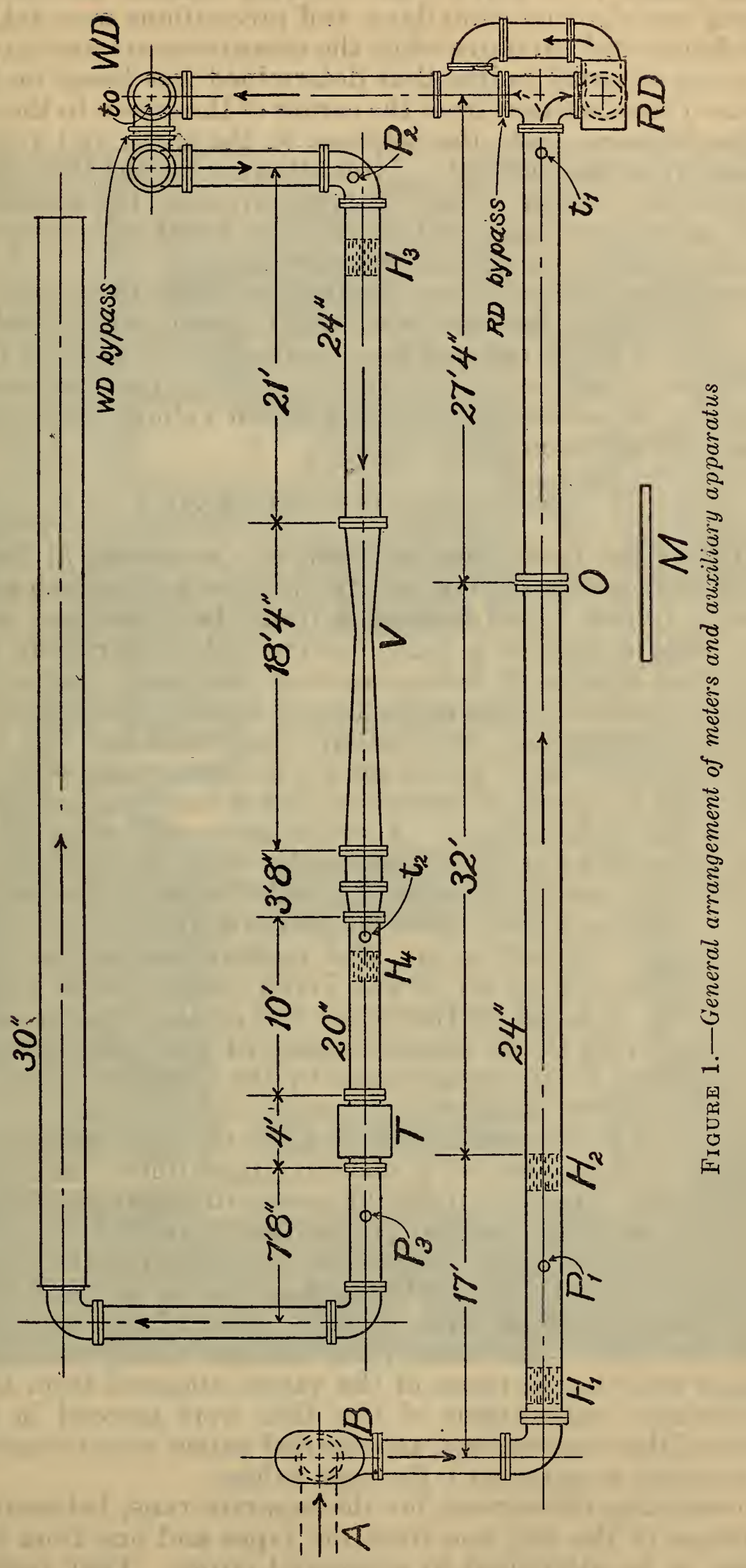


column by means of a surveyor's transit sighted on a rider which could be raised or lowered while bearing against the shell plates. This work was done on calm days, and precautions were taken to see that the holder did not move while the measurements were in progress.

The mean external radius thus determined was based on 42 measurements of the distances from the center of the crown to the columns; 63 of the distances from the columns to the shell; and 1,008 of the departures from the vertical. After allowing for the thickness of the plates and the volume of the internal bracing, the effective mean internal radius was computed to be 83.872 feet, giving an average horizontal cross section of 23,098 square feet.

The profile of the crown was determined along two nearly perpendicular diameters by means of a surveyor's level, and the volume was computed from the average of the two profiles. The fixed timbering inside the holder and above the water was measured and gave a small correction to be subtracted from the crown volume, which was thus found to be 106,294 cubic feet.

\section{HEIGHT MEASUREMENTS}

The fall of the holder during a run was measured at four points spaced nearly equally around the circumference. At each end of one diameter a bronze tape, suspended from the guide arm projecting from the edge of the crown, hung down into the water of the tank and could be read against an index mounted on a float. At each end of the diameter perpendicular to the first, a square copper wire, notched on one side to form a rack, was similarly suspended and was guided by rollers to engage a small pinion on a 4-dial gear train mounted on a float, so that any vertical motion of the holder was registered as a change of the dial readings. A preliminary calibration of the dial train was eflected by running it along the wire, stretched horizontally under the same tension as when suspended, with a tape beside it on which the distance moved could be read directly.

The reason for adopting the dial mechanisms was to permit of photographic recording, for it was found impracticable to get clear pictures of the divisions on the tapes; but all the measurements were ultimately referred to the tapes as standard, the tapes being read by two observers at a time signal given by the snapping of the cameras which photographed the dials.

If the holder tips to one side during the run, the measurements of the fall at opposite ends of a diameter may differ, but aside from accidental errors, their mean should agree with the mean of the values found at the ends of a diameter perpendicular to the first. Examination of the whole series of measurements, assuming the prelininary calibrations to be valid, showed that there were systematic differences between the mean of the dials and the mean of the tapes, and also between the dials. And since there was no reason to suspect any systematic error in the mean of the values obtained from the tapes, the preliminary calibrations of the dials were ignored in the final reduction of the observations, and the dial values were corrected so as, on the average, to agree with the tape values.

The remaining differences, for the separate runs, between the two mean values of the fall, one from the tapes and one from the dials, were then to be attributed to accidental errors. They ranged from 







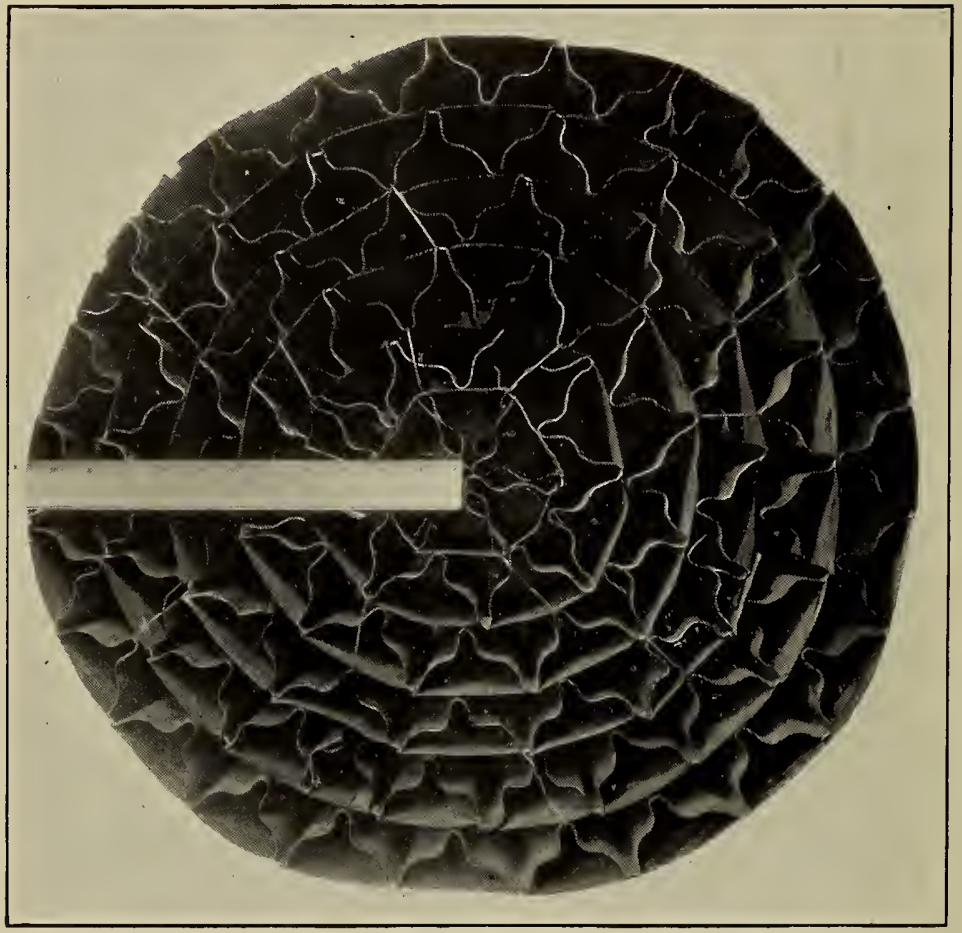

Figure 3.-Honeycomb 
nothing up to 1.7 per cent of the fall, with an average of \pm 0.43 per cent, and may have been due partly to bending of the tapes or wires by wind.

The wires were, of course, held taut by weights on their lower ends, but there was no evidence of a progressive stretching during the course of the experiments.

During a few of the earlier runs, dial mechanisms were used at all four stations. The readings from the dials that were thereafter replaced by tapes were corrected by comparison with the corrected readings from the other pair of dial trains, which was used throughout.

In addition to the fall of the holder during a run, it is also necessary to know the absolute value of the initial or final height of the edge of the crown above the water in the tank. The zero correction to be applied to the tape readings for this purpose was found by running a level line out from the edge of the crown and taking a reading on the tape.

\section{CONTROL AND MEASUREMENT OF TEMPERATURE}

The temperature of the air in the holder was measured by four, or later only three, resistance thermometers. Two of these were hung from the crown near the NW. side, about 8 and 18 feet down, respectively; one was about halfway from the center to the SE. side, a few feet below the crown; and one was a few feet below the crown at the center. This last thermometer became defective during the course of the experiments and was not used during the later runs.

The first attempt to control the temperature was by means of some 20 garden spray nozzles distributed under the crown so as to give a fairly uniform shower; and when this proved unsatisfactory, the sprays were placed on top of the crown. Ultimately, the holder was virtually water jacketed by flooding it with water, pumped up from the tank and allowed to run down again over the crown and sides in as uniform a film as possible. It was found that with a flow of 700 to 1,000 gallons per minute, the temperature of the water flowing over the crown did not change more than 1 or 2 degrees $\mathrm{F}$. from center to edge, even in a strong wind.

Uniformity of temperature was tested by means of a movable thermocouple. After the resistance thermometers had come to indicate uniformity within 0.5 degree, one junction of the couple was held near one of the resistance thermometers while the other was shifted about to a number of positions within the holder, and the difference in temperature of the junctions was found from the observed E. M. F. 'This was first tried on a cool, rainy, windy night without the flood in operation, and it was repeated on a rather cool calm night with a small flood stream. The greatest difference observed was about 1 degree $F$.

The experiments with the holder were made at night, most of them between midnight and $4 \mathrm{a}$. m., a time when the temperature of the outside air is usually falling slowly. If the temperature in the holder can not be held perfectly constant during the whole of a run, it is evidently desirable that it should fall rather than rise. For if the air is saturated at the start, it tends to remain saturated as it cools, whereas if the temperature rises, there is some doubt on this point unless the rise is very slow. 
In preparing for a run, the holder was filled by the booster, while water, about 5 degrees warmer than the water in the tank, was sprayed into the intake. Thus the air entered the holder saturated (this was tested by a psychrometer) at a temperature somewhat above that already existing in the holder, and remained saturated as it cooled down. To assist mixing by convection currents and to prevent the formation of fog, the internal sprays were usually turned on for a time after the holder was filled and before the run was started.

\section{LEAKAGE TEST}

Before starting to use the holder for experiments with air, it was purged of gas and the inlet from the gas mains sealed. It was then thoroughly cleaned and the water in the tank was renewed. It was next examined for leaks and those found were calked, after which it was filled with air, sealed off, and left for five days, during which observations of height, temperature, and barometric pressure were made from time to time, so that the amount of air in the holder could be computed. This test showed that, to the degree of accuracy of the observations, the holder was tight and that no leakage correction would be needed, even in the longest runs made with it.

\section{ORIFICE METER INSTALLATION}

\section{ORIFICES}

The orifice plates were made of one-eight inch Monel metal, and the orifices were cylindrical holes with square, sharp corners at both faces of the plate. The edges were examined under the microscope and in a few cases, where the upstream corner appeared not to be quite perfect, it was retouched with an oilstone or a dead smooth file laid flat on the face of the plate.

Centering in the pipe was adjusted by measurement from the cylindrical outer edge of the plate to three flats, $120^{\circ}$ apart on the upstream orifice flange, where the distances from the axis of the pipe were known.

The diameter of each orifice was measured in several azimuths by an inside micrometer, the range of the separate values obtained being of the order of \pm 0.002 inch for the larger orifices and somewhat less for the smaller ones. Values of the mean diameter $d$ are shown in column 2 of Table 1.

The mean of 11 measurements of the diameter of the pipe within 6 inches upstream from the orifice plate was $D=23.311$ inches, the diameter on the downstream side being about 0.01 inch larger. Values of the diameter ratio of the orifices, $d / D=\beta$, are shown in column 3 of the table. For convenient reference, the orifice plates were designated by the approximate values of the area ratio expressed in per cent, which are given in the first column. The values of $\beta^{4}$ given in the last column were frequently needed during the analysis of the experimental results. 
TABLE 1.-Dimensions of orifices

\begin{tabular}{|c|c|c|c||c|c|c|c|}
\hline $\begin{array}{c}\text { Area } \\
\text { ratio }\end{array}$ & $\begin{array}{c}\text { Diameter } \\
\mathrm{d}\end{array}$ & $\begin{array}{c}\text { Diameter } \\
\text { ratio } \beta\end{array}$ & $\boldsymbol{\beta}^{4}$ & $\begin{array}{c}\text { Area } \\
\text { ratio }\end{array}$ & $\begin{array}{c}\text { Diameter } \\
\mathrm{d}\end{array}$ & $\begin{array}{c}\text { Diameter } \\
\text { ratio } \beta\end{array}$ & $\beta^{4}$ \\
\hline Per cent & Ins. & & & & & \\
5 & 5.213 & 0.2236 & 0.0025 & $\begin{array}{c}\text { Per cent } \\
50\end{array}$ & $\begin{array}{c}\text { Ins. } \\
16.489\end{array}$ & 0.7073 & 0.2503 \\
10 & 7.374 & .3163 & .0100 & 55 & 17.299 & .7421 & .3033 \\
20 & 10.429 & .4474 & .0401 & 60 & 18.061 & .7748 & .3603 \\
30 & 12.776 & .5481 & .0902 & 65 & 18.800 & .8065 & .4230 \\
35 & 13.798 & .5919 & .1227 & 70 & 19.509 & .8369 & .4906 \\
40 & 14.748 & .6327 & .1602 & 75 & 20.187 & .8660 & .5624 \\
45 & 15.628 & .6704 & .2020 & 50 & 20.858 & .8946 & .6404 \\
\hline
\end{tabular}

\section{PIPE}

The straight run of smooth steel pipe ahead of the orifice, to the nearest fitting other than a simple flange joint, was 47 feet 2 inches; and on the downstream side it was 25 feet 6 inches. The first 10 feet on each side of the orifice consisted of two 5-foot lengths which had been machined smooth inside, the joints being dowelled so that they lined up within one thirty-second inch. The whole pipe, out to the distances mentioned above, was painted inside with graphite and oil and rubbed down, which gave it a very smooth surface.

\section{HONEYCOMBS}

To eliminate whirl or large eddies in the stream approaching the orifice, two honeycombs were mounted in the pipe. The first was near the entrance from the booster to the straight run of pipe, about 45 feet from the orifice, and the second was set with its downstream face 32 feet 2 inches or $16.5 \mathrm{D}$ from the orifice.

The honeycombs were 12 inches long in the direction of flow and each contained about 160 parallel passages or cells. They were built up of alternate rings of flat and of doubly-corrugated, 30-gage galvanized iron. The appearance of one of the honeycombs is shown in Figure 3, and those placed in the line ahead of the Venturi and Thomas meters were of similar construction.

\section{PRESSURE TAPS}

The side holes drilled through the pipe for taking off the pressures were one-eighth inch in diameter and were rounded off on the inside of the pipe to a radius of one thirty-second inch. Nipples for rubber tubing were soldered over the holes on the outside and could be joined by short rubber connectors to lengths of copper tubing, of about $1 / 4$-inch bore, leading to the manometers.

In all the observations for determining the discharge coefficients of the orifices, the same pair of holes was used. They were, respectively, 12 inches upstream and 6 inches downstream from the face of the nearer of the two flanges holding the orifice plate.

In the investigation of longitudinal distribution of pressure, measurements were made simultaneously at 46 holes, 14 upstream and 32 downstream. The first 10 of the upstream holes were in a line along the top of the pipe. The eleventh, distant 2 inches from the plate, was offset 1 inch to one side; the twelfth, distant 1 inch from the plate, was similarly offset to the other side; and the thir- 
teenth and fourteenth, also 1 inch from the plate, were at the ends of a horizontal diameter. The first 3 of the downstream holes corresponded in location to the last 3 of the upstream. The others were on 3 parallel lines, on top and 2 inches on either side, and were so arranged that no 2 holes on the same line were less than 4 inches apart. The longitudinal spacing of the holes used is shown in Tables 2 to 11 .

\section{WATER MANOMETERS}

All the pressures to be observed were low enough to be measured on open-water manometers 36 inches high. The manometers were made up in units of 4 each, the vertical glass tubes being 1 inch in diameter but drawn down at the ends to facilitate making connections. The lower ends of the 4 tubes were connected through cocks to a short header and thence to a common reservoir or tank near the top of the tubes. This tank had a free-water surface 8 inches in diameter and was provided with a 1-inch gage tube for observing the level of the water in the tank. It had a tight cover, with a nipple which could either be left open to the atmosphere or connected to one of the pressure taps. The upper ends of the manometer tubes could be connected to any desired pressure taps.

For the experiments on pressure distribution, 12 such units were provided. They were set up in line, as shown in Figure 2, and the 48 cocks were connected by links to a long, horizontal bar, so that they could all be closed simultaneously by moving a single lever. The water columns were thereby locked in position and the levels could then be determined at leisure by means of the cathetometers provided for making the readings. When the manometers were being used in this way, the separate tanks were connected to a common header.

Thermometers hung near the manometers gave the temperatures of the water columns with sufficient accuracy for making the small reduction to standard temperature.

\section{WET AND DRY BULB PSYCHROMETER}

Two mercurial thermometers were inserted through a rubber stopper in a hole in the wall of the pipe, and a wick around one of them was fed with water from outside, by a device which prevented any escape of air. This consisted of a small electrically heated boiler followed by a condenser, from which the condensate was led to the wick through a small copper tube extending for some distance along the inside of the pipe, so as to equalize the temperature. By adjusting the heating current, the water supply could be made just sufficient to keep the wick properly moistened.

Similar psychrometers were used at the other points in the line indicated in Figure 1.

\section{ROTARY DISPLACEMENT METER}

The location of the rotary displacement meter is shown in Figures 1 and 2. To give the temperature of the air entering it, a dry thermometer was inserted a few feet ahead of the meter at the point $t_{1}$ in Figure 1. The pressure was measured by one of the manometers connected to a tap some distance downstream from the orifice flanges, 
the drop from this point to the rotary meter being negligible at the comparatively low rates of flow to which this meter was limited. The humidity of the air was determined by the psychrometer ahead of the orifice station.

\section{VENTURI METER}

The Venturi tube used was the "Herschel standard Venturi tube" made by the Builders Iron Foundry. The holes into the piezometer rings were three-eighths inch in diameter and there were 12 at the entrance and 8 at the throat. The diameter at the entrance ring was 24.86 inches, and the throat diameter was 11.992 inches.

Ahead of the Venturi, there was a 19-foot straight run of 24-inch pipe to the flange of the next elbow, and a honeycomb was set with its downstream face 15.5 feet, or about $7.7 D$ from the upstream flange of the Venturi.

At the downstream end of the Venturi, a short nipple and a reducer, 3 feet 8 inches long together, led to a 10 -foot length of 20 -inch pipe and so to the Thomas meter.

The entrance and throat pressures were measured by a pair of the water manometers already described.

\section{AUXILIARY INSTRUMENTS AND OPERATIONS}

\section{REGULATION OF THE RATE OF FLOW}

The steam pressure at the turbine which drove the booster was not constant and the governor was rather sluggish; and since accuracy in the experiments required that the rate of flow along the test line should be constant during any one run, hand regulation was resorted to. An inclined draft gauge was set up near the turbine and connected to two taps near the orifice flange. An attendant, watching this gauge and with his hand on a lever attached to the throttle valve of the turbine, kept the gauge reading and therefore the rate of flow as constant as practicable during the course of any experiment.

\section{BAROMETER}

The barometer, of the Fortin type, was kept in a vault where the temperature was nearly constant. Its internal corrections had been determined by comparison with the standard barometer of the U.S. Weather Bureau Station in Chicago. Since the cistern of the barometer was 23 feet below the water level in the holder tank, a small altitude correction was applied in making computations that involved the absolute pressure in the holder.

The excess pressure inside the holder was read on a small, U-tube, water manometer at the center of the crown.

\section{CLOCK}

The time measurements needed in the experiments with the holder were made by means of.a high-grade pendulum clock with sweep seconds hand, which ran within a few seconds a day and was amply accurate, in comparison with the unavoidable errors in other parts of the work. 


\section{PHOTOGRAPHIC RECORDING}

Some of the more important readings were recorded photographically by cameras fitted with electromagnetically controlled shutters so that they could all be snapped at once by closing a single switch. By this means simultaneous pictures could be taken of the clock face, the dials on the mechanisms for measuring the fall of the holder, and the dials of the rotary displacement meter.

\section{VARIATION OF PRESSURE ALONG THE PIPE NEAR AN ORIFICE}

\section{EXPERIMENTS}

The experimental procedure in this part of the investigation was very simple. With an orifice plate in position and the manometers connected to a series of taps along the pipe, the booster was started and brought up to a constant speed, drawing air from outside and forcing it along the line through the orifice. After waiting till the water columns had become as nearly steady as was to be expected, they were fixed by closing all the cocks simultaneously, and the readings were then made with the cathetometers. Zero readings were made on the open gauge tubes on the common header, and the gauge pressure at each tap could then be found by subtraction.

Barometer readings were taken, to permit of reducing the results to absolute pressures, if desired, and the temperature of the air in the pipe was also recorded. The water columns were all at nearly the same temperature and since only comparative values of the pressures were needed, reduction to standard temperature was superfluous.

At least two such sets of observations, or runs, at different rates of flow, were made with each of the orifices listed in Table 1.

\section{MODE OF REPRESENTING THE RESULTS}

If the pressures, observed in the foregoing manner near an orifice installed in a straight pipe, are plotted against distance from the orifice, the resulting points lie along a curve of the familiar shape illustrated qualitatively in Figure 4, which also shows the notation adopted here for representing the results.

Starting with a tap several pipe diameters ahead of the orifice and going on to taps successively farther downstream, the static pressure observed at the wall of the pipe at first decreases slowly, as it does in steady flow along any straight pipe, but near the orifice the pressure begins to rise as the stream piles up against the plate. This upstream part of the curve is represented by $A B C$ in Figure 4.

At the rates of flow attained in these experiments, the preliminary fall was inappreciable except for the largest orifices, and the curve was sensibly a horizontal straight line for a considerable distance ahead of the point $B$ where the obstruction offered by the orifice plate began to make itself felt. Still farther upstream, the observations at the first two taps, which were 56 and 44 inches from the orifice, gave abnormally low values as is indicated by the dotted piece of curve starting at $A^{\prime}$ in Figure 4 . This was doubtless due to the proximity of a flange joint a little over 3 inches ahead of the first tap. There was probably a slight discontinuity in the line of the pipe 
wall here, for although the two sections of pipe had been machined smooth they were not perfectly round, and there was also a small change of mean diameter, the upstream section being about 0.04 inch larger than the section next the orifice in which the tap holes were located.

On the downstream side of the orifice plate, after the sharp drop from $C$ to $D$, the pressure falls to a minimum at $E$, rises to a maximum at $F$, and thereafter falls off slowly.

In order to compare the results obtained with any one orifice at different rates of flow with one another or with observations on other orifices, it is first necessary to reduce them all to some common basis, and this was done as follows:

The most probable value of the pressure $p_{2}$ at the downstream minimum, $E$, was found graphically by plotting and drawing a

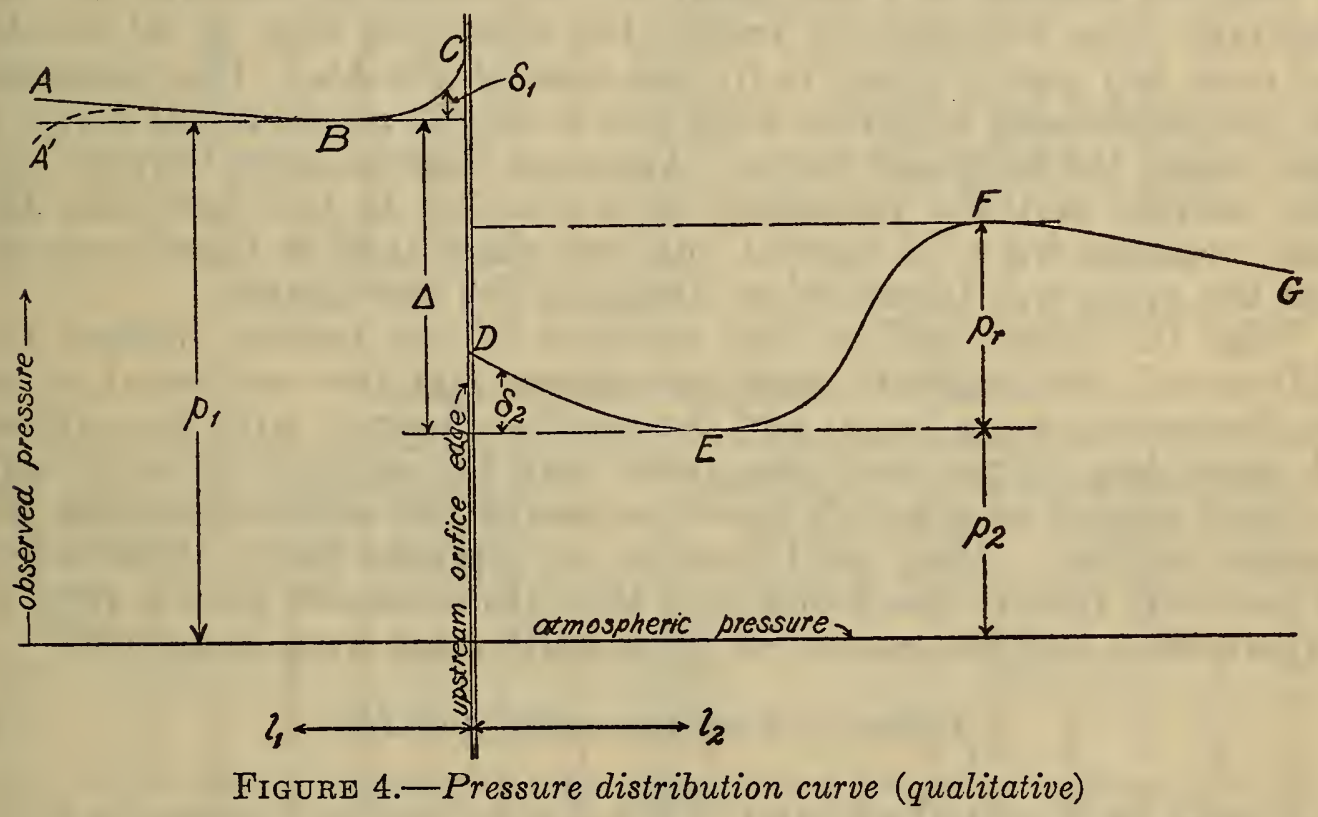

smooth curve, which gave an estimate based on several neighboring points. This minimum pressure was then subtracted from the pressure observed at each of the downstream taps and the difference was denoted by $\delta_{2}$, as illustrated in Figure 4.

For the upstream points, in the few instances in which there was a recognizable minimum at $B$, the minimum pressure $p_{1}$ was found graphically, as for $p_{2}$; but usually the reading's were so uniform that this was unnecessary and $p_{1}$ was taken to be this uniform pressure. The value of $p_{1}$ was then subtracted from each of the observed upstream pressures and the difference denoted by $\delta_{1}$.

When the values of $\delta_{1}$ and $\delta_{2}$ had been found, they were expressed as percentages of the difference of pressure, $p_{1}-p_{2}=\Delta$, between the upstream and downstream minima, and the various sets of observations were thus made comparable.

\section{TABLES OF RESULTS}

The results of the observations, expressed in the manner just described, are exhibited in Tables 2 to 11 , which are all arranged in the same way. 
The first column gives the distance in inches from the nearer face of the orifice plate to each of the taps at which the pressures were measured, starting with the tap farthest upstream. The decreasing numbers in the first part of the column refer to the upstream taps, and the increasing numbers in the second part to the downstream taps.

Each of the following columns, except the last, refers to a single run and gives the values found for $100 \delta_{1} / \Delta$ or $100 \delta_{2} / \Delta$, at the distances from the orifice shown in the first column. At the head of each of these columns certain data characteristic of the run are given, namely: (1) The differential $p_{1}-p_{2}=\Delta$ in inches of water; (2) the differential, expressed in per cent of the minimum upstream pressure, or 100 $\Delta / p_{1}=100 x$; and (3) the Reynolds number $R_{d}$ defined in note $\mathrm{B}$, divided by 100,000 .

The last column is a composite of the preceding columns for the separate runs, obtained by taking 100 times the sum of all the $\delta^{\prime} \mathrm{s}$ for each tap and dividing it by the sum of the $\Delta^{\prime} \mathrm{s}$. This amounts to the same thing as giving each run a weight proportional to its $\Delta$ and talking the weighted mean. Apparent discrepancies between the last column and the preceding ones are due to the fact that the computations were all carried out one place farther than is given, and the mean was taken before dropping the last figures.

With the larger orifices, the capacity of the booster limited the differential obtainable to such low values that the accidental errors of observation were large; and the results obtained with the orifices of more than 60 per cent area ratio were too irregular to be of any interest except as a rough continuation of the observations on the smaller orifices. They are therefore not reported here. After a few of the early runs it was found that the cathetometers were in need of adjustment, and the results of these early runs were discarded.

TABLE 2.-5 per cent orifice, $\beta=0.224$

\begin{tabular}{|c|c|c|c|c|c|c|c|c|c|c|c|c|c|}
\hline $\begin{array}{r}\Delta \text { in. } \mathrm{H}_{2} \mathrm{O}= \\
100 x= \\
10^{-5} R_{d}=\end{array}$ & $\begin{array}{l}2.33 \\
.58 \\
1.6\end{array}$ & $\begin{array}{l}2.71 \\
.68 \\
1.7\end{array}$ & $\begin{array}{l}15.48 \\
3.74 \\
4.2\end{array}$ & $\begin{array}{l}18.06 \\
4.44 \\
4.4\end{array}$ & $\begin{array}{l}31.74 \\
7.40 \\
5.8\end{array}$ & & 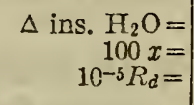 & $\begin{array}{l}2.33 \\
.58 \\
1.6\end{array}$ & $\begin{array}{r}2.71 \\
.68 \\
1.7\end{array}$ & $\begin{array}{c}15.48 \\
3.74 \\
4.2\end{array}$ & $\begin{array}{c}18.06 \\
4.44 \\
4.4\end{array}$ & $\begin{array}{c}31.74 \\
7.40 \\
5.8\end{array}$ & \\
\hline $\begin{array}{c}\text { Inches } \\
\end{array}$ & $\begin{array}{r}-0.8 \\
-.7 \\
-.3 \\
.0\end{array}$ & $\begin{array}{r}-0.3 \\
.4 \\
-.1 \\
-.1\end{array}$ & $\begin{array}{r}-0.4 \\
.2 \\
.1 \\
.1\end{array}$ & $\begin{array}{r}-0.3 \\
-.1 \\
.0 \\
.0\end{array}$ & $\begin{array}{r}-0.2 \\
-.1 \\
.0 \\
.0\end{array}$ & $\begin{array}{r}-0.3 \\
.1 \\
.0 \\
.0\end{array}$ & 22 & $\begin{array}{l}.0 \\
.0 \\
.0 \\
.0\end{array}$ & $\begin{array}{l}.1 \\
.1 \\
.1 \\
.0\end{array}$ & $\begin{array}{r}.0 \\
.0 \\
-.0 \\
-.1\end{array}$ & $\begin{array}{r}.0 \\
.0 \\
-.0 \\
-.2\end{array}$ & $\begin{array}{l}1 \\
.1 \\
.1 \\
.0\end{array}$ & $\begin{array}{l}1 \\
1 \\
0 \\
0\end{array}$ \\
\hline -. & $\begin{array}{r}.0 \\
.0 \\
-.2 \\
-.2\end{array}$ & $\begin{array}{r}-.1 \\
-.1 \\
.3 \\
.3\end{array}$ & $\begin{array}{l}.1 \\
.0 \\
.0 \\
.0\end{array}$ & $\begin{array}{l}.0 \\
.0 \\
.0 \\
.0\end{array}$ & $\begin{array}{l}.0 \\
.0 \\
.0 \\
.0\end{array}$ & $\begin{array}{l}.0 \\
.0 \\
.0 \\
.0\end{array}$ & & $\begin{array}{l}.0 \\
.0 \\
.0\end{array}$ & $\begin{array}{l}.0 \\
.0 \\
.0 \\
.0\end{array}$ & $\begin{array}{l}. \\
.0 \\
.0 \\
.0 \\
2\end{array}$ & $\begin{array}{l}.0 \\
.0 \\
.0 \\
.0 \\
0\end{array}$ & 0 & $\begin{array}{l}0 \\
.0 \\
.0\end{array}$ \\
\hline & $\begin{array}{r}.2 \\
.2 \\
-.2 \\
-.2\end{array}$ & $\begin{array}{l}.3 \\
.3 \\
.1 \\
.1\end{array}$ & $\begin{array}{l}.0 \\
.3 \\
.3 \\
.0\end{array}$ & $\begin{array}{l}.0 \\
.0 \\
.0 \\
.1\end{array}$ & $\begin{array}{l}.0 \\
.0 \\
.0 \\
.1\end{array}$ & $\begin{array}{l}.0 \\
.1 \\
.1 \\
.1\end{array}$ & & $\begin{array}{r}.0 \\
1.4 \\
1.4\end{array}$ & $\begin{array}{r}.0 \\
.6 \\
1.7\end{array}$ & 1.0 & $\begin{array}{r}.1 \\
.9 \\
1.5\end{array}$ & .3 & A. \\
\hline & $\begin{array}{l}.3 \\
.5\end{array}$ & $\begin{array}{r}-.1 \\
.0\end{array}$ & .4 & $\begin{array}{r}.5 \\
.4\end{array}$ & $\begin{array}{l}.5 \\
.5\end{array}$ & 4 & 6 & $\begin{array}{l}3.4 \\
4.1\end{array}$ & $\begin{array}{l}2.9 \\
2.9 \\
4.8\end{array}$ & $\begin{array}{l}3.1 \\
4.3\end{array}$ & $\begin{array}{l}\text { 3. } \\
\text { 3. } \\
4.4\end{array}$ & $\begin{array}{l}2.6 \\
4.0\end{array}$ & $\begin{array}{l}2.1 \\
2.8 \\
4.2\end{array}$ \\
\hline & $\begin{array}{l}5 \\
.3 \\
.3\end{array}$ & $\begin{array}{l}-.3 \\
-.1\end{array}$ & .2 & $\begin{array}{r}3 \\
.2\end{array}$ & 4 & $\begin{array}{l}.3 \\
.3\end{array}$ & & 4. 9 & 3 & 5.4 & .1 & 5.1 & 5. 2 \\
\hline & .0 & - & .0 & & & .1 & & 5 & & $\begin{array}{l}\text { 5. } \\
6.0 \\
6.0\end{array}$ & 9 & $\begin{array}{l}5.6 \\
6.0 \\
6.1\end{array}$ & $\begin{array}{l}6.0 \\
6.1\end{array}$ \\
\hline & $\begin{array}{l}.0 \\
.0\end{array}$ & $\begin{array}{l}-.7 \\
-.3\end{array}$ & $\begin{array}{l}.0 \\
.0\end{array}$ & $\begin{array}{l}-.1 \\
-.1\end{array}$ & ? & $\begin{array}{l}.0 \\
.0\end{array}$ & 130 & 5.9 & 6.0 & 6. & 6.1 & 6.2 & \\
\hline & $\begin{array}{r}0 \\
.0\end{array}$ & $\begin{array}{r}-.1 \\
.1\end{array}$ & $\begin{array}{l}.0 \\
.0\end{array}$ & $\begin{array}{l}.0 \\
.0\end{array}$ & & & & & & & & & \\
\hline
\end{tabular}


TABLE 5.-30 per cent orifice, $\beta=0.548$

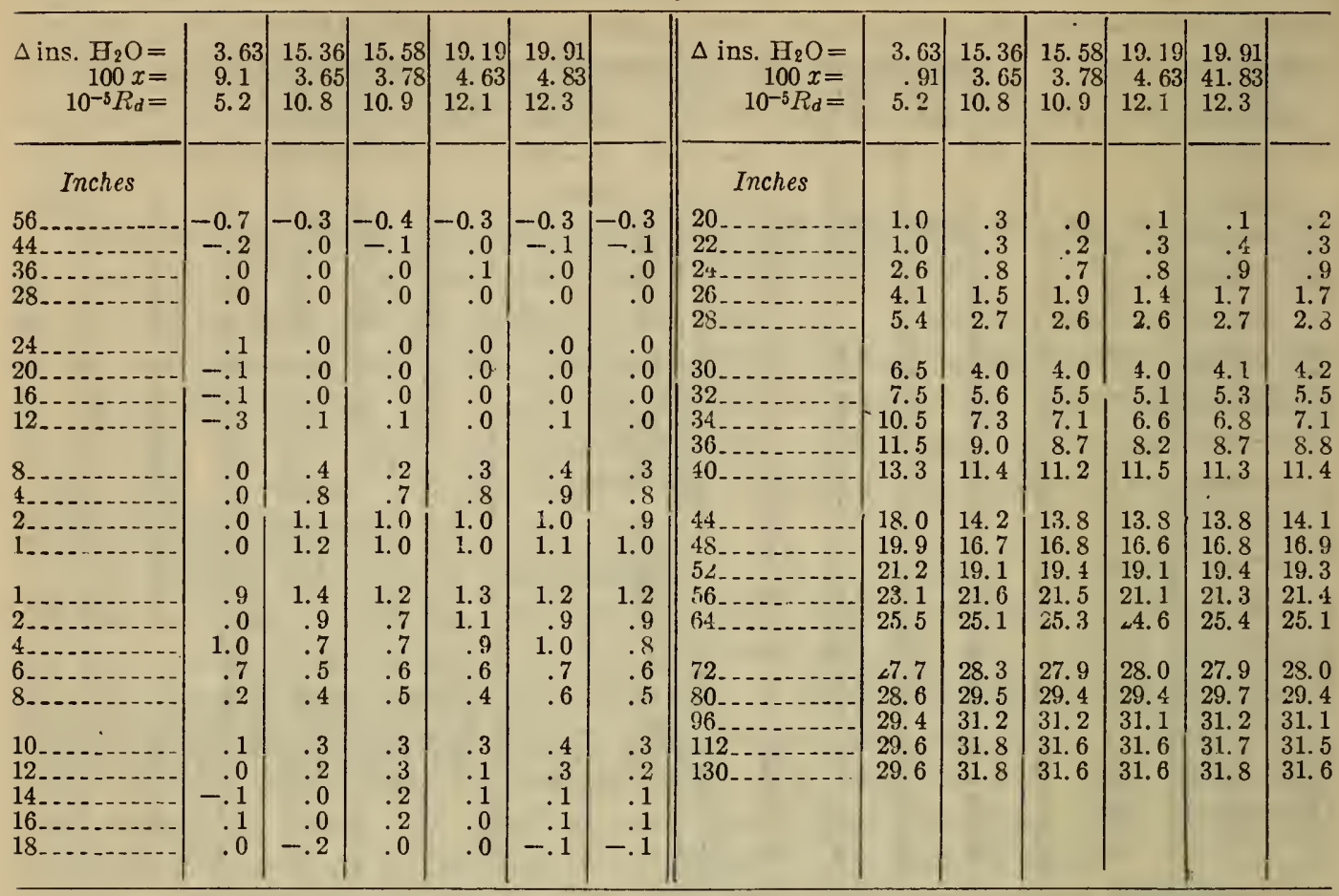

TABLE 6. -95 per cent orifice, $\beta=0.592$

\begin{tabular}{|c|c|c|c|c|c|c|c|c|c|c|c|}
\hline $\begin{array}{r}\Delta \text { ins. } \mathrm{H}_{2} \mathrm{O}= \\
100 x= \\
10^{-5} R_{d}=\end{array}$ & $\begin{array}{l}3.34 \\
0.84 \\
5.6\end{array}$ & $\begin{array}{l}3.35 \\
0.84 \\
5.6\end{array}$ & $\begin{array}{r}12.35 \\
3.03 \\
10.7\end{array}$ & $\begin{array}{l}15.41 \\
3.74 \\
11.9\end{array}$ & & $\begin{array}{r}\Delta \text { ins. } \mathrm{H}_{2} \mathrm{O}= \\
100 x= \\
10^{-5} R_{d}=\end{array}$ & $\begin{array}{l}3.34 \\
0.84 \\
5.6\end{array}$ & $\begin{array}{l}3.35 \\
0.84 \\
5.6\end{array}$ & $\begin{array}{r}12.35 \\
3.03 \\
10.7\end{array}$ & $\begin{array}{l}15.41 \\
3.74 \\
11.9\end{array}$ & \\
\hline Inches & & & & & & Inches & & & & & \\
\hline $\begin{array}{l}56 .- \\
44 .- \\
36-- \\
28 .-\end{array}$ & $\begin{array}{r}-0.4 \\
.0 \\
.0 \\
.0\end{array}$ & $\begin{array}{r}-0.6 \\
-.6 \\
.0 \\
.0\end{array}$ & $\begin{array}{r}-0.4 \\
.0 \\
.0 \\
.1\end{array}$ & $\begin{array}{r}-0.3 \\
-.1 \\
.1 \\
.1\end{array}$ & $\begin{array}{r}-0.3 \\
-.1 \\
.0 \\
.1\end{array}$ & $\begin{array}{l}20 . \\
22 . \\
24 . \\
26 . \\
28 .\end{array}$ & $\begin{array}{l}2.1 \\
3.2 \\
4.7 \\
6.3 \\
8.1\end{array}$ & $\begin{array}{l}1.7 \\
3.5 \\
4.5 \\
6.5 \\
8.1\end{array}$ & $\begin{array}{r}.4 \\
1.1 \\
2.1 \\
3.8 \\
5.7\end{array}$ & $\begin{array}{r}.9 \\
1.3 \\
2.7 \\
4.0 \\
5.6\end{array}$ & $\begin{array}{l}1 . \\
2 . \\
4 . \\
5 .\end{array}$ \\
\hline 24 & .0 &.- .2 & .0 & .0 & .0 & 30 & 97 & 9.5 & 75 & 7.5 & 7 \\
\hline.- & .2 & .0 & .0 & .0 & .0 & 32 & 11.2 & 11. 5 & 8.7 & 9.0 & $\ddot{\theta}$ \\
\hline $12 \ldots$ & .2 & .0 & .0 & .0 & .0 & 34 & 13.4 & $\begin{array}{l}13.8 \\
16\end{array}$ & 10.9 & 11.3 & 11. \\
\hline & 5 & 0 & 4 & .4 & .4 & 40 & $\begin{array}{l}18.0 \\
18.0\end{array}$ & 18.7 & $\begin{array}{l}16.0 \\
16.4\end{array}$ & 15.8 & 15. \\
\hline & 6 & $\begin{array}{l}1.1 \\
1.6\end{array}$ & $\begin{array}{l}1.2 \\
1.5\end{array}$ & $\begin{array}{l}1.2 \\
1.3\end{array}$ & $\begin{array}{l}1.1 \\
1.3\end{array}$ & & 22.4 & 22.0 & 19.9 & 18.8 & 19. \\
\hline $1 .-$ & 1.3 & 1.3 & 1.5 & 1. 4 & 1.4 & & 24.4 & & 22. 9 & 20.2 & 22. \\
\hline & 2. 3 & 1.7 & 1.4 & 1.4 & 1.5 & & 27.9 & $2 \delta .6$ & 27.9 & 26.3 & 26 \\
\hline & & 1.7 & & 1. 1 & 1. 1 & 64 & 31.0 & 30.6 & 31.4 & 30.3 & 30. \\
\hline 2. & 1.2 & $\begin{array}{l}1.0 \\
1.0\end{array}$ & 4 & .7 & .8 & & 33.7 & 33.0 & 34.7 & 32.9 & 32. \\
\hline & .9 & .2 & .3 & .5 & .4 & & & 35.0 & 36.6 & 33. 7 & 34. \\
\hline & 4 & .2 & .4 & 2 & .3 & 112 & 35.6 & 35.9 & 39.0 & 36.4 & 36. \\
\hline & 2 & .0 & 2 & .3 & .2 & & 35.5 & 36.1 & 39.0 & 36.4 & 36. \\
\hline & .1 & .0 & -.1 & .2 & .0 & & & & & & \\
\hline & 2 & .2 & .1 & .0 & .1 & & & & & & \\
\hline
\end{tabular}


TABLE 7.-40 per cent orifice, $\beta=0.633$

\begin{tabular}{|c|c|c|c|c|c|c|c|c|c|c|c|}
\hline 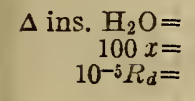 & $\begin{array}{l}2.89 \\
.73 \\
5.7\end{array}$ & $\begin{array}{l}3.95 \\
.99 \\
6.6\end{array}$ & $\begin{array}{l}9.74 \\
2.42 \\
10.4\end{array}$ & $\begin{array}{l}10.64 \\
2.61 \\
10.9\end{array}$ & & 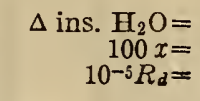 & $\begin{array}{l}2.89 \\
.73 \\
5.7\end{array}$ & $\begin{array}{l}3.95 \\
.99 \\
6.6\end{array}$ & $\begin{array}{l}9.74 \\
2.42 \\
10.4\end{array}$ & $\begin{array}{l}10.64 \\
2.61 \\
10.9\end{array}$ & \\
\hline Inches & $\begin{array}{r}-1.2 \\
-.5 \\
.0 \\
.0 \\
.0 \\
-.1 \\
-.1 \\
-.1 \\
.1 \\
1.4 \\
1.4 \\
1.9 \\
2.7 \\
2.4 \\
1.6 \\
1.2 \\
.8 \\
.5 \\
.3 \\
.1 \\
.0 \\
.3\end{array}$ & $\begin{array}{r}-0.2 \\
-.1 \\
.0 \\
.0 \\
.0 \\
.1 \\
.1 \\
.1 \\
.3 \\
1.2 \\
1.3 \\
1.6 \\
1.8 \\
1.2 \\
.8 \\
.7 \\
.1 \\
.1 \\
.1 \\
.1 \\
.3 \\
.8\end{array}$ & $\begin{array}{r}-0.2 \\
-.1 \\
.1 \\
.1 \\
.0 \\
.0 \\
.0 \\
.0 \\
.3 \\
1.5 \\
1.7 \\
1.9 \\
1.6 \\
1.2 \\
.6 \\
.5 \\
.5 \\
.3 \\
.2 \\
.0 \\
-.1 \\
.0\end{array}$ & $\begin{array}{r}-0.2 \\
-.1 \\
.0 \\
.0 \\
.0 \\
.0 \\
.0 \\
.0 \\
.4 \\
1.6 \\
2.0 \\
2.1 \\
1.4 \\
1.0 \\
.6 \\
.4 \\
.3 \\
.2 \\
.1 \\
.1 \\
.0 \\
.2\end{array}$ & $\begin{array}{r}-0.3 \\
-.1 \\
.0 \\
.0 \\
.0 \\
.0 \\
.0 \\
.0 \\
.3 \\
1.5 \\
1.7 \\
1.9 \\
1.7 \\
1.2 \\
.7 \\
.6 \\
.4 \\
.3 \\
.2 \\
.1 \\
.0 \\
.2\end{array}$ & $\begin{array}{l}\quad \text { Inches } \\
20 \\
224 \\
26 \\
30 \\
32 \\
34 \\
40 \\
44 \\
482 \\
564 \\
64 \\
80 \\
96 \\
112 \\
130\end{array}$ & $\begin{array}{r}1.8 \\
3.7 \\
5.0 \\
7.1 \\
9.7 \\
11.3 \\
12.1 \\
14.8 \\
17.6 \\
18.5 \\
25.0 \\
27.1 \\
29.1 \\
31.8 \\
34.0 \\
36.3 \\
38.1 \\
39.2 \\
39.9 \\
39.9\end{array}$ & $\begin{array}{r}1.9 \\
4.2 \\
6.0 \\
7.7 \\
9.5 \\
11.9 \\
14.0 \\
16.5 \\
17.5 \\
22.5 \\
25.4 \\
27.6 \\
30.4 \\
32.6 \\
35.8 \\
38.0 \\
39.2 \\
40.6 \\
41.1 \\
41.0\end{array}$ & $\begin{array}{r}1.2 \\
2.8 \\
4.7 \\
6.6 \\
8.5 \\
11.0 \\
13.1 \\
15.1 \\
16.8 \\
20.5 \\
\\
23.6 \\
26.8 \\
29.6 \\
32.0 \\
35.0 \\
37.3 \\
39.1 \\
40.6 \\
41.0 \\
41.0\end{array}$ & $\begin{array}{r}1.3 \\
2.8 \\
4.5 \\
6.4 \\
8.5 \\
10.5 \\
12.8 \\
14.6 \\
16.8 \\
20.4 \\
23.9 \\
27.0 \\
29.5 \\
31.2 \\
34.5 \\
37.5 \\
38.9 \\
40.2 \\
40.8 \\
40.8\end{array}$ & $\begin{array}{r}1.4 \\
3.1 \\
4.8 \\
6.7 \\
8.8 \\
10.9 \\
13.0 \\
15.1 \\
17.0 \\
20.5 \\
24.1 \\
27.0 \\
29.6 \\
31.8 \\
34.8 \\
37.4 \\
38.9 \\
40.3 \\
40.8 \\
40.8\end{array}$ \\
\hline
\end{tabular}

TABLE 8. -45 per cent orifice, $\beta=0.670$

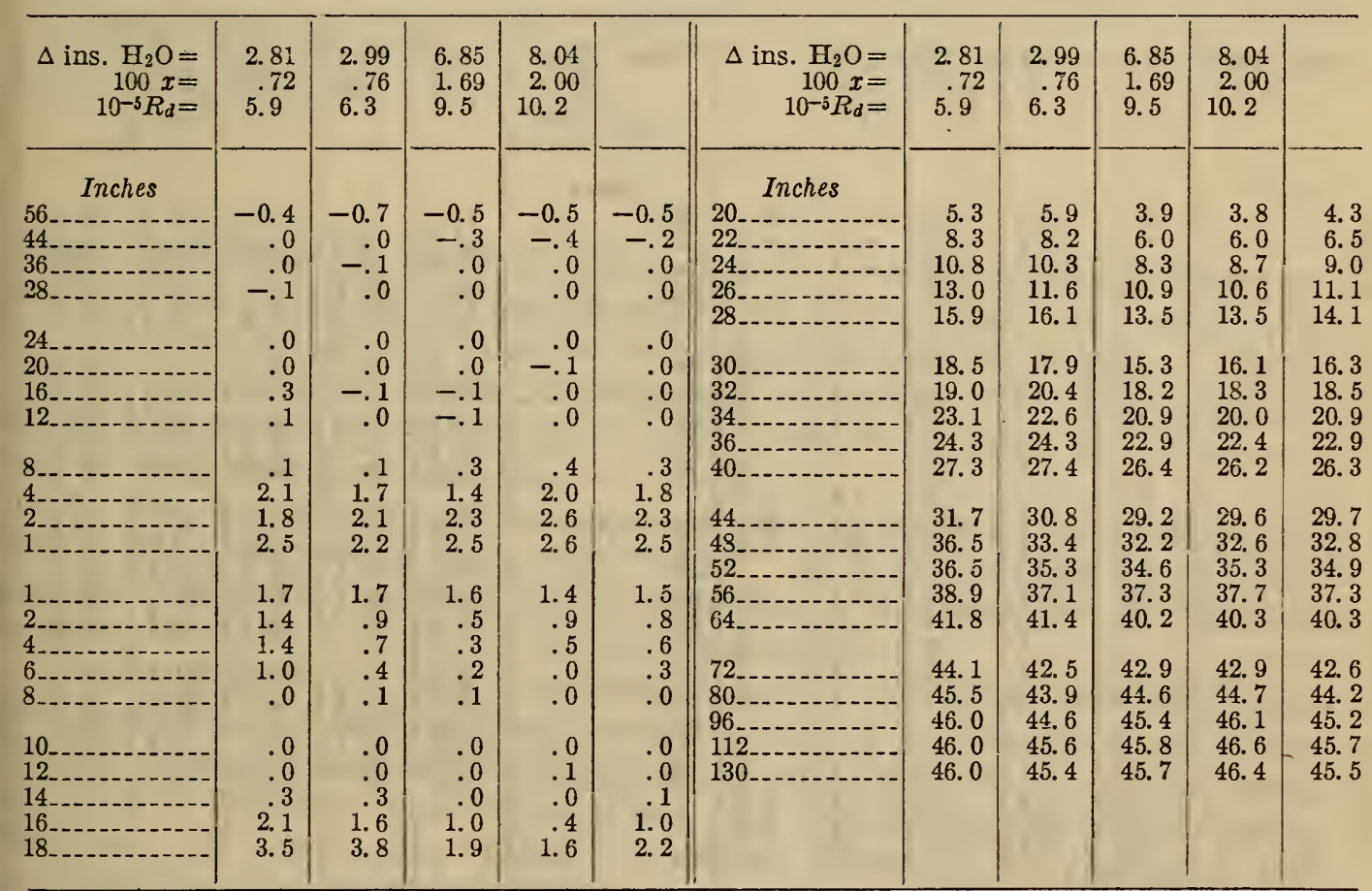


TABLE 9.-50 per cent orifice, $\beta=0.707$

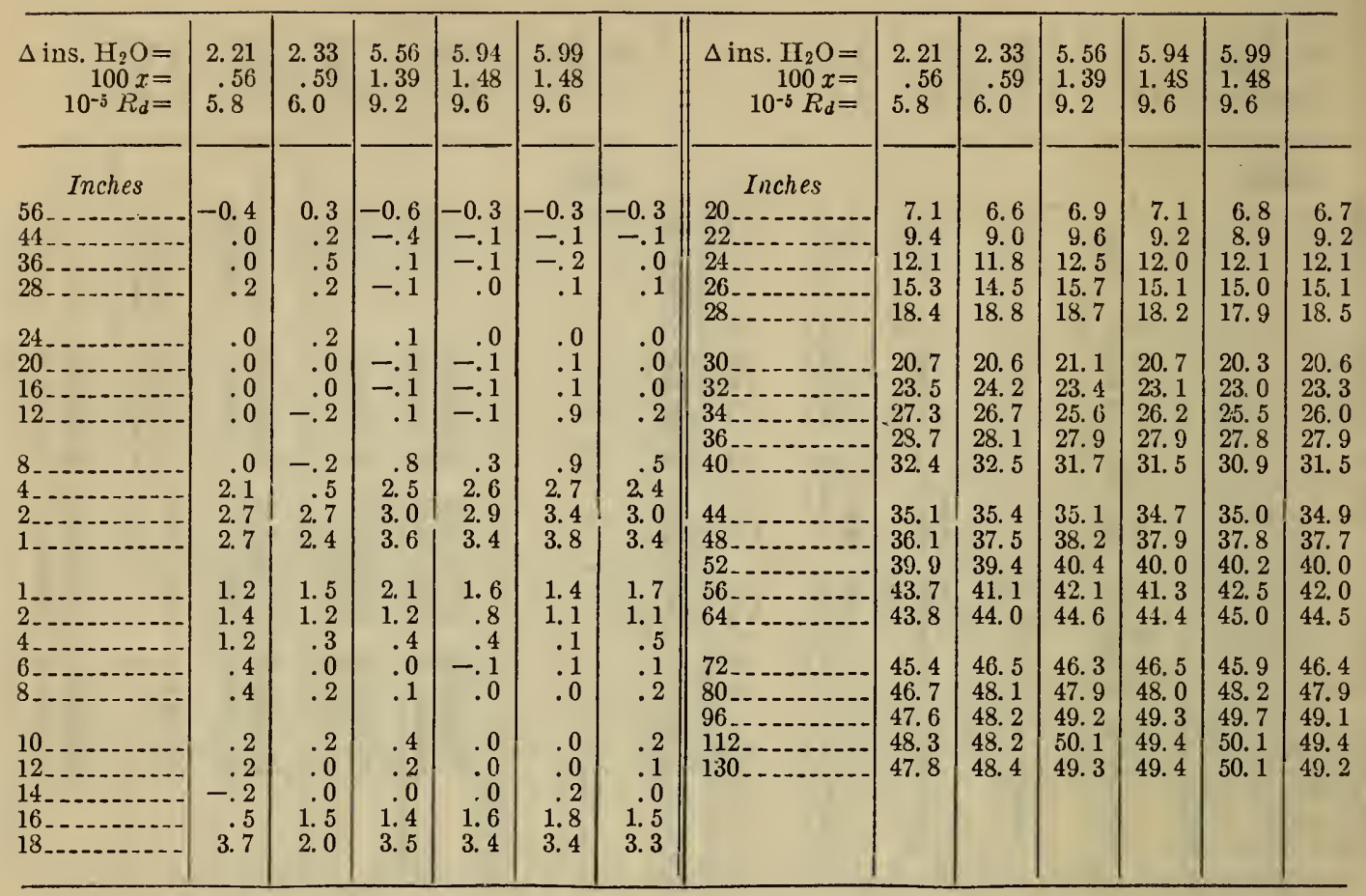

TABLE 10.-55 per cent orifice, $\beta=0.742$

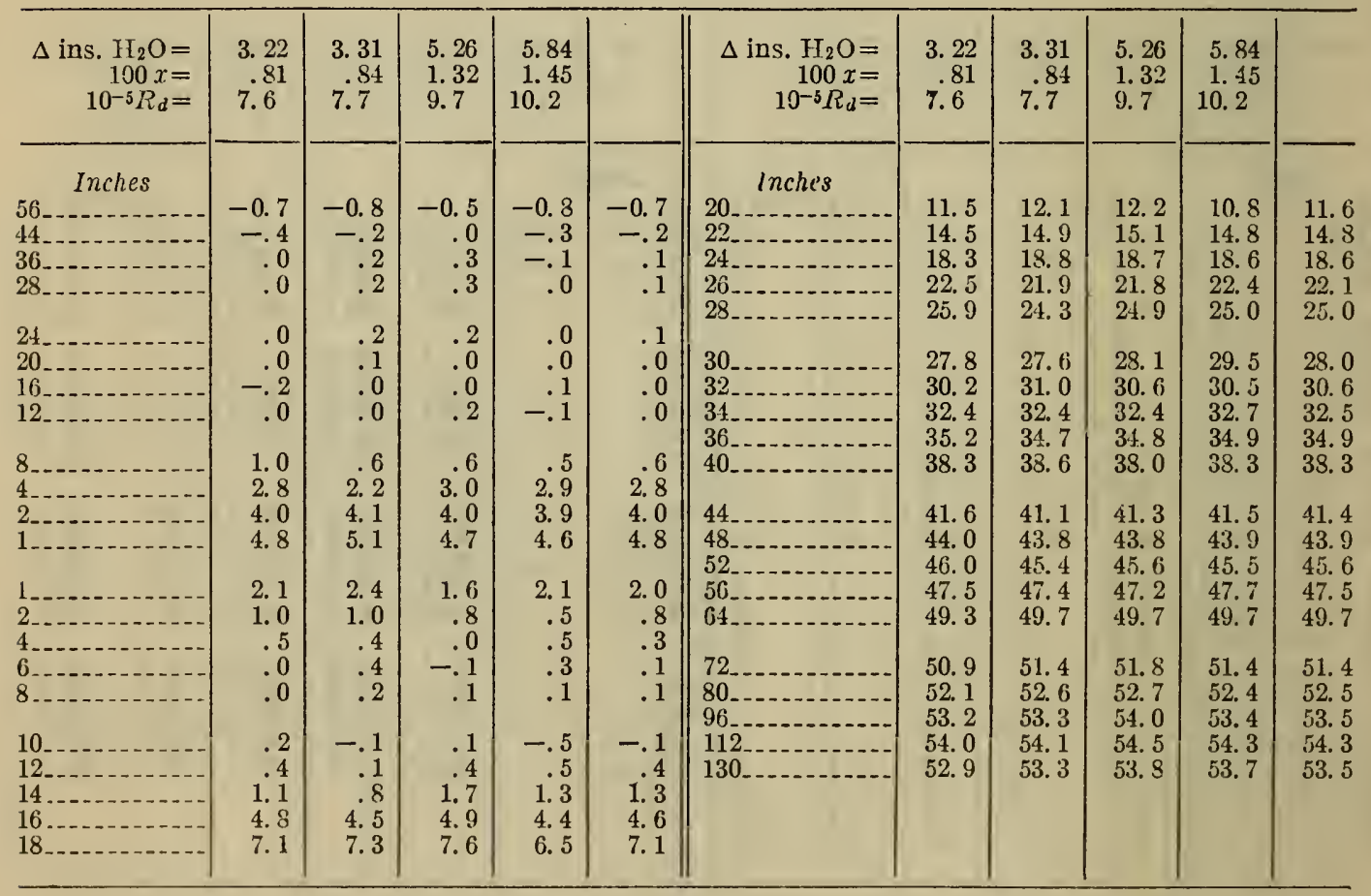


TABLE 11.-60 per cent orifice, $\beta=0.775$

\begin{tabular}{|c|c|c|c|c|c|c|c|c|c|c|c|}
\hline 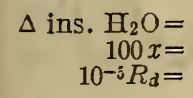 & $\begin{array}{l}1.25 \\
0.31 \\
5.1\end{array}$ & $\begin{array}{l}1.64 \\
0.41 \\
5.9\end{array}$ & $\begin{array}{l}4.24 \\
1.04 \\
9.4\end{array}$ & $\begin{array}{l}4.40 \\
1.10 \\
9.7\end{array}$ & & 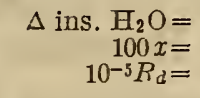 & $\begin{array}{l}1.25 \\
0.31 \\
5.1\end{array}$ & $\begin{array}{l}1.64 \\
0.41 \\
5.9\end{array}$ & $\begin{array}{l}4.24 \\
1.04 \\
9.4\end{array}$ & $\begin{array}{l}4.46 \\
1.10 \\
9.7\end{array}$ & \\
\hline In & & & & & & Inches & & & & & \\
\hline & -0.6 & $\begin{array}{l}-1.4 \\
-5\end{array}$ & -0.7 & -1.0 & -0.9 & & 18. 6 & $\begin{array}{r}20.1 \\
24.2\end{array}$ & $\begin{array}{l}18.3 \\
21.5\end{array}$ & 16. 6 & $\begin{array}{l}17.8 \\
21.4\end{array}$ \\
\hline & .6 & .0 & .2 & .6 & .4 & 24 & 24.2 & 28.1 & $\begin{array}{l}2.0 \\
25.9\end{array}$ & $\begin{array}{l}20.0 \\
23.6\end{array}$ & $\begin{array}{l}21.4 \\
25.0\end{array}$ \\
\hline & .0 & & & .4 & .2 & & & $\begin{array}{r}31.9 \\
34.9\end{array}$ & 29.1 & 26.9 & $\begin{array}{l}28.7 \\
21.6\end{array}$ \\
\hline & .0 & .0 & .1 & .4 & .2 & & & & & & \\
\hline & $\begin{array}{r}.0 \\
-.3\end{array}$ & $\begin{array}{l}.0 \\
.2\end{array}$ & .0 & .0 & .0 & & $\begin{array}{l}34.3 \\
37.7\end{array}$ & $\begin{array}{l}37.2 \\
39.1\end{array}$ & $\begin{array}{l}36.0 \\
371\end{array}$ & $\begin{array}{l}33.7 \\
35 .\end{array}$ & $\begin{array}{l}34.9 \\
36.7\end{array}$ \\
\hline & .3 & .0 & .1 & .0 & .1 & & 39.9 & 41.2 & 40.0 & 38.0 & 39.3 \\
\hline & .6 & 2 & .1 & .8 & .4 & $\begin{array}{l}0 . \\
40\end{array}$ & 43.7 & 45.8 & $\begin{array}{l}41.9 \\
44.6\end{array}$ & $\begin{array}{r}5.0 \\
42.4\end{array}$ & $\begin{array}{l}41.1 \\
43.7\end{array}$ \\
\hline & 3.8 & 3.8 & 3. 6 & 3.5 & $\begin{array}{l}3.6 \\
5 .\end{array}$ & . & 178 & 180 & 175 & & \\
\hline & 6.9 & 6.5 & 6.1 & 6.4 & 6.4 & 48 & 49.4 & 50.6 & 49.1 & 46.3 & 48.6 \\
\hline & & 17 & 30 & 26 & 25 & & 50.0 & 51.1 & 51.3 & 503 & 50 \\
\hline & 1. 9 & 1. 0 & $\begin{array}{r}0.0 \\
.4\end{array}$ & 1. 2 & .9 & 64 & 52.2 & 54.4 & 54.1 & 52.3 & 52.1 \\
\hline & .9 & .0 & ${ }_{1}^{0}$ & $\begin{array}{r}.0 \\
.0\end{array}$ & .0 & & & 55,6 & & & \\
\hline & 0 & & & & .0 & & 58.2 & & 56.7 & 54 & 56.0 \\
\hline & .0 & & & .0 & & & 58.2 & 56.8 & 58.4 & 56.1 & 57.2 \\
\hline & & 2. 2 & & & 1. 2 & 130 & 58.2 & 56.6 & 57.5 & 55.1 & 56.4 \\
\hline & $\begin{array}{l}3.5 \\
7.2\end{array}$ & $\begin{array}{r}5.5 \\
10.1\end{array}$ & $\begin{array}{l}3.6 \\
9.6\end{array}$ & $\begin{array}{l}3.3 \\
8 \quad 7\end{array}$ & 3.6 & & & & & & \\
\hline & 12.0 & 14.6 & 13.2 & 11.1 & 12.4 & & & & & & \\
\hline
\end{tabular}

\section{VARIATION OF PRESSURE DISTRIBUTION WITH SPEED OF FLOW}

If the data obtained in the different runs with any one orifice are plotted in the form

$$
\frac{100 \delta}{\Delta}=f(l)
$$

where $l=$ distance from the orifice plate, it is found that the upstream parts of the resulting curves do not show any certain variation with $\Delta$. If there is any systematic variation within the range of differentials and speeds covered in these experiments, it is masked by the accidental errors of measurement which are evident in the irregularities of each series of points.

On the downstream side, however, the systematic change of the curve with increasing $\Delta$ is quite clear. It is illustrated by the two curves of Figure 5, each of which represents the mean of two runs at nearly the same $\Delta$, with the 45 per cent orifice.

As the differential and the speed through the orifice are increased, the minimum corresponding to the point $E$ of Figure 4 is blown farther downstream and the subsequent rapid rise occurs a little later. At points between the orifice plate and the downstream minimum, increasing $\Delta$ lowers the value of $100 \delta_{2} / \Delta$, although the change is not great within the range of these experiments.

Both these effects are more pronounced for large than for small diameter ratios, and a given change of $\Delta$ has more effect when $\Delta$ is still small than when it is larger. One gets the impression that as $\Delta$ increases, the curves for any one orifice tend to approach a final form asymptotically.

$60869-31-8$ 
With a given gas flowing through any one orifice, the curve of pressure distribution along the wall of the pipe is fixed by the values of the Reynolds number and the fractional differential, $\Delta / p_{1}=x$. In the present experiments, the Reynolds number was always so high as to

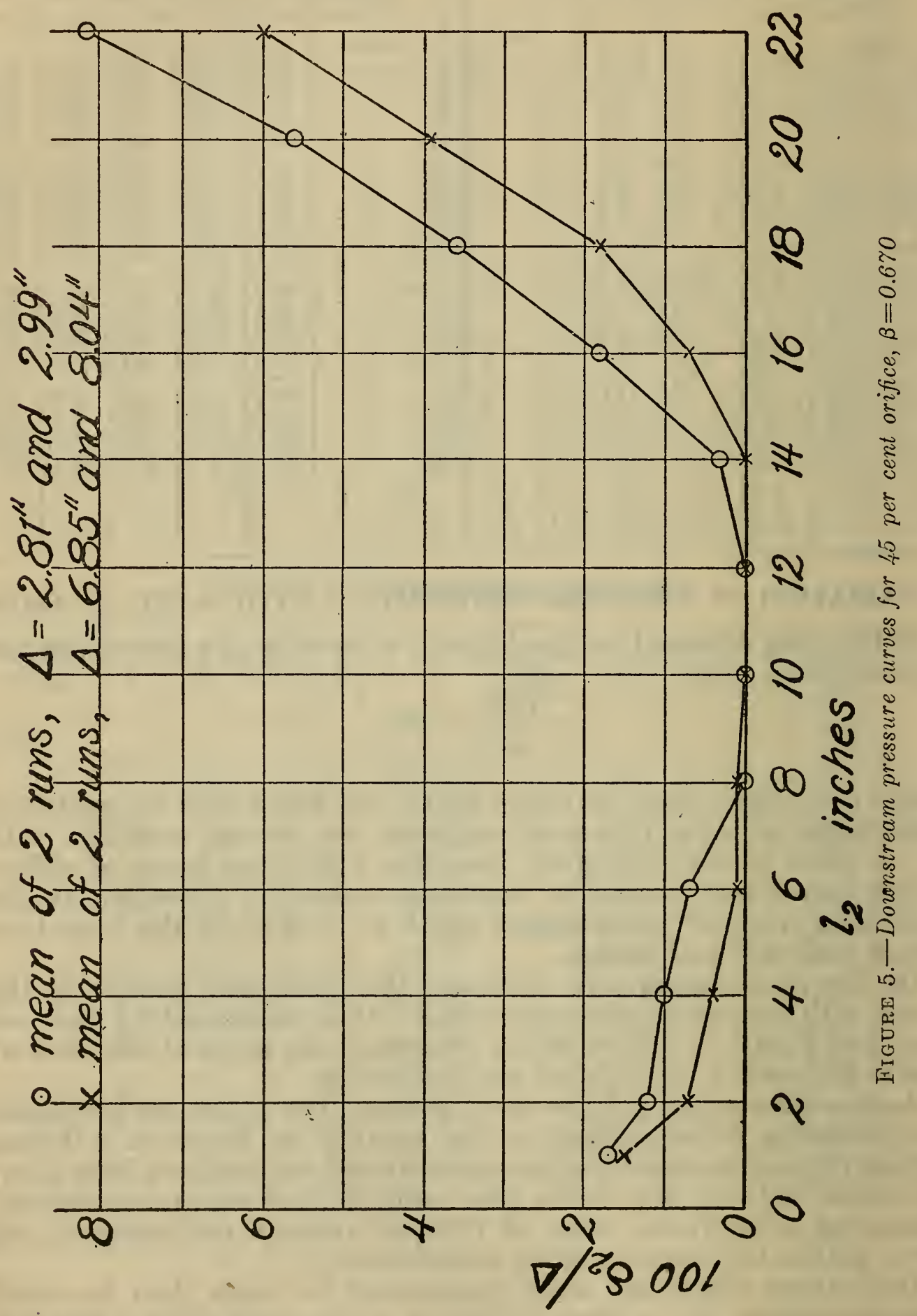

make the effects of viscosity insignificant; and the change of the downstream part of the curve with $\Delta$-or with $x$, since $p_{1}$ was nearly constant-is probably to be attributed to the same cause as the simultaneous change of the adiabatic discharge coefficient, namely, the lateral expansion of the gas in the jet after passing the orifice, due to the excess of static pressure at the axis of the jet over that at the 
boundary. ${ }^{2}$ This view of the matter is consistent with the fact that the upstream part of the pressure curve is much less affected by changes in $\Delta$ than the downstream part.

\section{VARIATION WITH DIAMETER RATIO}

If points are plotted from the composite data in the final columns of Tables 2 to 11, smooth mean cuves drawn through the points are of the same general shape as found by other observers. Sample plots are given in Figure 6 for the 20 and 40 per cent orifices $(\beta=0.447$ and 0.633 ) from $l_{1}=20$ inches to $l_{2}=28$ or 52 inches. Since $\delta_{1}$ is measured from the upstream and $\delta_{2}$ from the downstream minimum, and since the difference between these minimum pressures is $\Delta=100$ on the given scale, a consistent picture of the distribution of pressure over the whole length of the figure would require that the ordinates of the upstream points be increased by 100 .

As the diameter ratio, $\beta$, is increased, the downstream minimum becomes more pronounced and moves up toward the orifice, in the well-known manner; and the following maximum moves in the same direction, though it is so flat as to be difficult to locate at all closely.

For area ratios up to $\beta^{2}=0.6$, the rise of pressure from the downstream minimum to the maximum, expressed as a fraction of the drop from the upstream to the downstream minimum $\left(p_{\tau} / \Delta\right.$ in fig. 4$)$, is roughly equal to $\beta^{2}$ or "the restoration of pressure is equal to the area ratio," a convenient practical rule which we have not seen stated in just this form.

\section{EXPERIMENTS WITH THE HOLDER}

\section{PROCEDURE}

After the holder had been filled with air, in preparation for a run, and the connections of the booster rearranged, the resistance thermometers were read continuously, in rotation, until they showed that the temperature had become nearly uniform and constant. The booster was then started and brought up to the speed necessary to give the desired rate of flow along the line, and the attendant at the turbine throttle kept this rate as nearly constant as practicable throughout the ensuing run.

Since the mean rate of outflow of air was to be computed from the initial and final states of the holder, no intermediate observations on the holder were needed if all went well. But to avoid having to waste a whole run of which only a part was for any reason unsatisfactory, each run was divided into five periods with records of the height taken at six known instants, so that those periods for which the observations on the holder and on the meters under test were satisfactory could be utilized and the others discarded.

The resistance thermometers were read at about the times when the height was measured. The readings of each thermometer were plotted against the times when they were made, a mean curve was drawn, and the mean temperature in the holder at the instant of taking each height record was found from this curve.

E. Bucikingham, Note on Contraction Coefficients of Jets of Gas, B. S. Jour. Research, 6; May, 1931; or Techn. Mech. u. Thermodyn., May, 1231. 
Barometer readings were made occasionally, and if they changed enough during the run to make it worth while, the corrected values of the pressure were plotted against the times, and the pressures at the times of taking the height records were found graphically. The excess

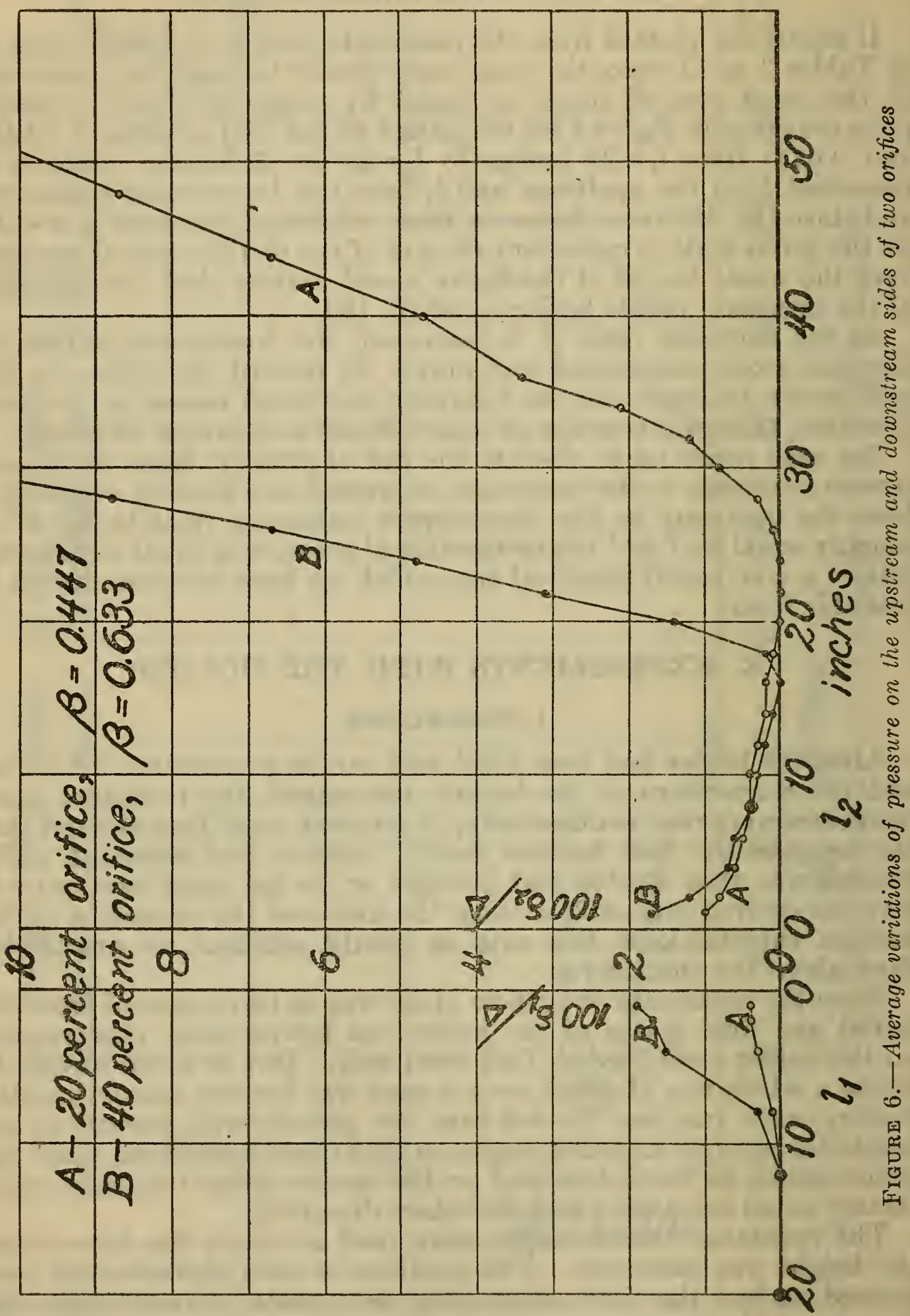

pressure inside the holder, shown by the gauge on the crown, was sensibly constant throughout the experiments.

When an orifice or the Venturi was under test, it was desirable to have as many readings as possible of the differential, so as to average 
out the accidental fluctuations due to the unavoidable slight unsteadiness of the rate of flow. Measurements were therefore made continuously, as often as an observer, or sometimes two observers, could sight and read the cathetometers. The temperatures of the wet and dry bulb thermometers changed slowly and regularly and did not need to be read so often - the average interval between readings was about 11 minutes. The computations relating to the Venturi and the orifices were based on the averages of the observed values of the differential, the static pressure, and the wet and dry bulb temperatures.

Since the rotary displacement meter registers the total volume passed and not the instantaneous rate, all that was needed for comparison with the observations on the holder was the mean density of the air entering the meter and the photographs of its dials, taken simultaneously with the measurements of the height of the holder. The mean density was computed from the average values of the static pressure and the wet and dry bulb temperatures.

\section{SATURATION IN THE HOLDER}

In computing the mass of air in the holder, it has to be assumed that the air is saturated with water vapor, and it is important that the assumption be as nearly true as possible. Initial saturation was ensured by spraying warm water into the intake of the booster while filling the holder, but if the temperature of the air had risen much during a run, the evaporation from the tank might not have been rapid enough to maintain saturation. In most of the runs to be reported on, the mean temperature in the holder either fell or remained constant, and in the remainder, the most rapid rate of rise was 1.0 degree per hour.

In the first reduction of the observations, immediately after the experiments, the values found for the discharge coefficient of the Venturi varied irregularly by much more than could possibly be attributed to the accidental errors of observation at the Venturi, and the indications seemed to be that there must have been errors of 5 degrees or more in the measurements of the mean temperature of the holder. After the care that had been taken, such errors seemed not merely very disappointing, but quite incredible, and an indirect check on the holder temperatures was therefore carried out.

In passing through the booster, the air from the holder was heated much more than enough to offset the simultaneous compression, and when it entered the line it was considerably less than saturated. At the beginning of a run, the inside of the booster was still wet from the water sprayed in while filling the holder, but it dried off as the run proceeded, and the pyschrometers along the line showed that the vapor content of the air, after first decreasing, reached a constant value, indicating that the drying was complete.

It seemed safe to assume that when this steady state of partial saturation had been attained, the air was neither depositing nor taking up any appreciable amount of water since leaving the holder, and that the percentage composition of the air-vapor mixture was the same in the line as it had been in the holder. On this assumption, it was very easy to calculate from the wet and dry bulb temperatures and the pressure at any point in the line, together with the known pressure in the holder, what the vapor pressure in the holder 
must have been, and thence, by means of the vapor pressure curve, to find what the temperature must have been if the air was saturated. This could then be compared with the temperature indicated by the resistance thermometers, and the agreement was found to be quite as good as could be expected.

In a few cases, the wet bulb readings were very irregular and indicated that the water supply to the wick had been deficient; but omitting these exceptional cases, the remaining 29 computations gave a maximum difference of 2.3 degrees between observed and calculated holder temperatures, and an average difference of only 0.63 degree.

The success of this check restored our confidence in the measurements of the temperature in the holder, and it was soon thereafter discovered that the discrepancies that had led to the check were spurious and due to a systematic mistake in one part of the computations.

\section{COMPUTATION OF THE RATE OF FLOW OF DRY AIR ALONG THE LINE}

In general, the mass of moist air that leaves the holder during any interval of time is not equal to the decrease of the mass contained in the holder. For if the temperature falls, vapor is precipitated and vanishes into the tank without having gone out through the booster; and if the temperature rises, vapor which did not exist at the start appears, from nowhere, as it were, by evaporation from the water in the tank. Furthermore, some vapor is added after the siir leaves the holder by the drying out of the booster during the initial stages of a run, as mentioned above. But the mass of dry air that leaves the holder is equal to the difference of the masses present at the beginning and end of the run, and this same mass is discharged through each of the meters installed in series in the line. It is therefore most convenient to base all the computations on masses of dry air, and we have first to find the mass of dry air contained in the holder at any instant for which the temperature, pressure, and volume are known from observation.

Let

$t\left({ }^{\circ} \mathrm{F}.\right)=$ the temperature of the air in the holder;

$p$ (inch $\left.\mathrm{Hg}, 32^{\circ}\right)=$ its absolute pressure;

$e_{s}\left(\right.$ inch $\left.\mathrm{Hg}, 32^{\circ}\right)=$ the saturation pressure of water vapor at $t^{\circ}$;

$\rho_{a}\left(\mathrm{lbs} . / \mathrm{ft}^{3}\right)^{3}=$ the density of dry air at $p, t$;

$V\left(\mathrm{ft}^{3}\right)^{3}=$ the volume of the holder at the observed height; and

$W_{a}$ (lbs.) = the mass of dry air contained in it.

On the assumption that the air is saturated, the partial pressure of the dry air is $\left(p-e_{s}\right)$, and if the vapor were all removed by absorption, without changing the temperature or the volume, the pressure of the remaining dry air would be $\left(p-e_{s}\right)$. If the volume were then reduced, isothermally, in the ratio $\left(p-e_{s}\right) / p$, the pressure would increase to $p$ and the resulting density would be $\rho_{a}$. Hence the mass of dry air (which has not been changed by these operations) is

$$
W_{a}=\frac{p-e_{s}}{p} V \rho_{a}
$$


Now let subscripts 1 and 2 refer to conditions at the beginning and end of a run.

Let

$z$ (minutes) $=$ the duration of the run; and

$M_{a}$ (lbs./sec.) = the mean rate of outflow of dry air.

Then evidently

$$
M_{a}=\frac{\left(W_{a}\right)_{1}-\left(W_{a}\right)_{2}}{60 z}
$$

or by (1)

$$
M_{a}=\frac{V_{1} X_{1}-V_{2} X_{2}}{z}
$$

where

$$
X=\frac{\left(p-e_{3}\right) \rho_{a}}{60 p}
$$

Values of $X$ may be tabulated in terms of $p$ and $t$ as arguments and, after the table has been constructed, the values of $X_{1}$ and $X_{2}$ may be found by interpolation.

The required values of $e_{s}$ were taken from the Wärmetabellen issued by the Reichsanstalt in 1919, and the values of $\rho_{a}$ were found as follows. The density of dry air containing the normal amount of $\mathrm{CO}_{2}$, at $32^{\circ} \mathrm{F}$. and under a pressure of 29.921 inches of mercury, at $32^{\circ}$ and with $g=32.161 \mathrm{ft} . / \mathrm{sec}^{2}$, as at Chicago, was taken to be 0.08070 lb./ft. ${ }^{3}$ This value was deduced from the results of $\mathrm{Ph}$. A. Guye's discussion of the best available data, as summarized in Landolt and Börnstein's Tables, 5th ed., 1923, vol. 1, p. 43. The mean coefficient of expansion of dry air at atmospheric pressure between $32^{\circ}$ and $122^{\circ} \mathrm{F}$., in terms of the volume at $32^{\circ}$ is very close to $1 / 490$ (not $1 / 492$ ). Hence we have, for the density of dry air at $t^{\circ} \mathrm{F}$. and an absolute pressure of $p$ inches of mercury at $32^{\circ}$, at Chicago,

$$
\rho_{a}=\frac{0.08070 \times 490 p}{29.921(458+t)}=\frac{1.3216 p}{458+t}
$$

And upon combining this with (4) we have the equation

$$
X=0.022026 \frac{p-e_{s}}{458+t}
$$

by means of which the table to be used with equation (3) was computed.

4. COMPUTATION OF THE DENSITY AND RATE OF FLOW OF MOIST AIR AT ANY SECTION OF THE LINE

Let

$t\left({ }^{\circ} \mathrm{F}.\right) \quad=$ the temperature of the air at the given section;

$p($ inch $\mathrm{Hg})=$ the static pressure there;

$e$ (inch $\mathrm{Hg})=$ the partial pressure of the water vapor;

$\rho$ (lbs./ft. $\left.{ }^{3}\right)=$ the density of the moist air; and

$M$ (lbs./sec.) = the rate of flow of moist air past the section.

The value of $t$ is given by the dry bulb thermometer, and $e$ is found from $p, t$, and the wet bulb depression, by means of Table 75 in Smithsonian Meteorological Tables (4th ed.), 1918. 
Taking the ratio of the molecular weights of water vapor and air to be $18.02 / 28.95=0.622$, and using the same fundamental data as for equation (5), we have

$$
\rho=\frac{1.3216(p-0.378 e)}{458+t}
$$

The rate of mass flow of the mixture of dry air and vapor is greater than that of the dry air alone by the amount of vapor carried along with the air. The pressure of the mixture being $p$, the partial pressure of the dry air in it is $(p-e)$ and the ratio of the mass of vapor to the mass of air in any quantity of the mixture is $0.622 e /(p-e)$. Hence the mass of the mixture is greater than the mass of the dry air contained in it, in the ratio

$$
\frac{p-e+0.622 e}{p-e}=\frac{p-0.378 e}{p-e}
$$

and the rate of mass flow of the mixture past the point in question is

$$
M=M_{a} \frac{p-0.378 e}{p-e}
$$

where $M_{a}$ is the mass flow of dry air computed from the observations on the holder by means of equations (3) and (6).

In addition to the rate of flow in pounds per second, it is convenient to have the rate also expressed in the more roundabout, but more familiar way as cubic feet per hour under standard conditions, and this may be accomplished as follows.

Let $Q$ ( $\mathrm{ft}^{3}$ /hour) be the volume rate of flow past a section of the line where the temperature is $t$, the static pressure $p$, and the vapor pressure $e$, measured at the density $\rho$ corresponding to these conditions. Then evidently

$$
Q=\frac{3,600 M}{\rho}
$$

and upon substitution of the values of $M$ from (8) and $\rho$ from (7) this takes the form

$$
Q=\frac{3,600(458+t)}{1.3216(p-e)} M_{a}
$$

Now let the standard conditions be $t=60$ ( ${ }^{\circ} \mathrm{F}$.),$p=30$ (inches $\mathrm{Hg}$ ), and $e=0.26$ (inches $\mathrm{Hg}$ ), which corresponds to 50 per cent relative humidity at $60^{\circ}$. Then if $Q_{s}$ is the value $Q$ would have if standard conditions prevailed at the section in question, and if we substitute the standard values in equation (10), the result is

$$
Q_{s}\left(\mathrm{ft}^{3} / \text { hour }\right)=47,450 M_{a}(\text { lbs./sec.) }
$$

and $Q_{s}$ is the volume flow of moist air under the standard conditions that would carry the actual mass flow of dry air computed from the observations on the holder. 
In the gas industry, "standard conditions" are usually understood to be 30 inches, $60^{\circ}$, and complete saturation. For these conditions, the figure 47,450 should be increased by about 0.9 per cent.

\section{REDUCTION OF THE OBSERVATIONS ON THE ORIFICES}

The results of the tests of the orifices will be given as values of "the hydraulic discharge coefficient, based on the upstream density and with the approach factor included." This coefficient, which was denoted by $C^{\prime}{ }_{1}$ in B. S. Research Paper No. $49^{3}$, will be denoted here by $C$. It may be defined, in terms of British absolute units, by the equation

$$
M=C \frac{\pi}{4} d^{2} \sqrt{2 \rho_{1} \Delta}
$$

in which, $M=$ the rate of flow, in lbs./sec.; $d=$ the diameter of the orifice, in feet; $\rho_{1}=$ the density of the moist air, in lbs. $/ \mathrm{ft}^{3}$ at the upstream pressure, temperature, and humidity; and $\Delta=$ the differential in poundals per square foot.

In practice, the diameter $d$ was measured in inches, and the catbetometer scales were graduated in centimeters, so that the differential was read in centimeters of water at the prevailing temperature. Upon introducing these units and supposing the differential to have been reduced to $\mathrm{cm}$. of water at $32^{\circ} \mathrm{F}$., equation (12) may be put into the form

$$
C=\frac{15.975 M}{d^{2} \sqrt{\rho_{1} \Delta}}
$$

And after introducing the values of $M$ from equation (8), and of $\rho_{1}$ from equation (7), we have

in which:

$$
C=\frac{13.896 M_{a}}{d^{2}(p-e)} \sqrt{\frac{(p-0.378 e)(458+t)}{\Delta}}
$$

$M_{a}$ (lbs./sec.) = the mass flow of dry air computed from the observations on the holder, as described above under 3 ;

$d$ (inches) $=$ the diameter of the orifice;

$t\left({ }^{\circ} \mathrm{F}.\right)=$ the temperature shown by the dry bulb thermometer ahead of the orifice;

$p$ (inches $\mathrm{Hg}, 32^{\circ}$ ) $=$ the absolute pressure at the upstream tap;

$e$ (inches $\mathrm{Hg}, 32^{\circ}$ ) $=$ the partial pressure of the water vapor as found from $p, t$, and the wet bulb depression; and

$\Delta\left(\mathrm{cm} \mathrm{H}_{2} \mathrm{O}, 32^{\circ}\right)=$ the observed differential, after reduction to $32^{\circ} \mathrm{F}$.

\section{REDUCTION OF THE OBSERVATIONS ON THE VENTURI}

The observations on the Venturi may be reduced in the same way as those on the orifices, and the results will first be given as values of $C$ computed by means of equation (14), with $d$ representing the diameter of the Venturi throat.

They will also be given as values of the "adiabatic" discharge coefficient because this permits of more direct comparison with

B. S. Jour. Research, 2, p. 561; March, 1929. 
values for water; and since the adiabatic coefficient is usually understood not to include the factor which allows for the speed of approach, it will be given in that form. It is then to be coinputed from the values of $C$ already found from equation (14) by means of the equation (see note A)

$$
C_{a}=C\left[\frac{2(1-r)\left(1-\beta^{4} r^{1,0}\right)}{7\left(r^{10}+\frac{10}{9}-r^{12^{2}}\right)}\right]^{\frac{1}{3}}
$$

in which $r=p_{2} / p_{1}$ and $\beta=d / D, D$ being the diameter of the Venturi at the entrance section, where the upstream pressure $p_{1}$ is observed.

\section{REDUCTION OF THE OBSERVATIONS ON THE ROTARY DISPLACE- MENT METER}

The results of the tests of the rotary displacement meter may be stated most conveniently by giving the values found for the quantity

$$
C_{d}=\frac{M}{M_{d}}
$$

in which $M$ is the mean rate of mass flow through the meter, computed from the observations on the holder, and $\dot{M}_{d}$ is the mean rate indicated by the displacement meter. It may be called the coefficient of the meter, and it is evidently the factor by which the rate shown by the meter must be multiplied to make it agree with the rate computed from the observations on the holder, which is treated as the absolute standard.

The "dial factor" of the meter, or the volume of gas taken in per revolution, was given by the makers as 9.6789 cubic feet per revolution. Hence if the photographs of the dials taken at the beginning and end of a run of $z$ minutes duration showed a difference of $n$ revolutions, the mean rate of volume flow indicated by the meter was

$$
V=\frac{9.6789 n}{60 z}\left(\mathrm{ft}^{3} / \mathrm{sec} .\right)
$$

measured at the upstream density at which the gas was taken in.

The expression for this upstream density is given by equation (7) and we therefore have

$$
M_{d}=\frac{9.6789 n}{60 z} \times \frac{1.3216(p-0.378 e)}{458+t}
$$

The mass flow computed from the observations on the holder is given by equation (8) and upon combining equations (8), (16), and (18) we have

in which

$$
C_{d}=4.6907 \frac{M_{a} z(458+t)}{n(p-e)}
$$

$M_{a}$ (lbs./sec) = the mass flow of dry air;

$z$ (minutes) $=$ the duration of the run;

$n=$ the difference of the initial and final dial readings;

$t\left({ }^{\circ} \mathrm{F}.\right)=$ the mean temperature of the air entering the meter;

$p$ (inches $\mathrm{Hg} 32^{\circ} \mathrm{F}$.) $=$ its mean absolute static pressure; and

$e$ (inches $\mathrm{Hg} 32^{\circ} \mathrm{F}$.) $=$ the mean partial pressure of the vapor in it 


\section{RESULTS OF THE EXPERIMENTS WITH THE HOLDER}

\section{GENERAL CHARACTERISTICS OF THE RUNS}

Table 12 gives certain information regarding the 43 separate runs made with the holder, the runs being numbered and listed approximately in the order of increasing rate of flow, shown in column 3 in thousands of cubic feet per hour at standard density.

TABLE 12.-Characteristics of the holder runs

\begin{tabular}{|c|c|c|c|c|c|c|c|}
\hline $\begin{array}{l}\text { Numiber } \\
\text { of run }\end{array}$ & $\begin{array}{l}\text { Date, } \\
1924\end{array}$ & $\begin{array}{l}\text { Rate of } \\
\text { 1low } \\
\frac{Q_{s}}{1,000}\end{array}$ & $\begin{array}{c}\text { Duration } \\
\text { of run } \\
z\end{array}$ & $\begin{array}{l}\text { Fall of } \\
\text { holder } \\
H_{1}-H_{2}\end{array}$ & $\frac{100 \epsilon}{H_{1}-H_{2}}$ & $\begin{array}{c}\text { Fall of } \\
\text { tempera- } \\
\text { ture } \\
t_{1}-t_{2}\end{array}$ & $\frac{100 \delta \Delta}{\Delta}$ \\
\hline $\mathbf{i}$ & 2 & 3 & 4 & 5 & 6 & $y$ & 8 \\
\hline $\begin{array}{l}0 . \mathrm{B} \\
1 \\
2 \\
3 \\
4\end{array}$ & $\begin{array}{cc}\text { Mo. } & \text { Day } \\
8 & 28 \\
8 & 29 \\
9 & 6 \\
8 & 20 \\
9 & 7\end{array}$ & $\begin{array}{l}22.7 \\
34.2 \\
35.2 \\
37.9 \\
39.8\end{array}$ & $\begin{array}{c}\text { Minutes } \\
300 \\
120 \\
200 \\
240 \\
270\end{array}$ & $\begin{array}{c}\text { Feet } \\
5.4 \\
3.2 \\
5.4 \\
7.2 \\
8.6\end{array}$ & $\begin{array}{r}0.13 \\
.31 \\
.04 \\
-.38\end{array}$ & $\begin{array}{r}{ }^{\circ} F . \\
0.5 \\
.5 \\
.6 \\
.2 \\
1.3\end{array}$ & $\begin{array}{r}23.1 \\
2.1 \\
1.1 \\
.6\end{array}$ \\
\hline $\begin{array}{l}5 \\
6 \\
7 \\
8 \\
9\end{array}$ & $\begin{array}{rr}9 & 10 \\
9 & 11 \\
9 & 8 \\
9 & 5 \\
9 & 10\end{array}$ & $\begin{array}{l}52 \\
55 \\
59 \\
62 \\
72\end{array}$ & $\begin{array}{r}105 \\
100 \\
180 \\
234 \\
60\end{array}$ & $\begin{array}{r}4.2 \\
4.3 \\
8.3 \\
11.4 \\
3.5\end{array}$ & $\begin{array}{r}-.83 \\
1.69 \\
.33 \\
-.55 \\
.08\end{array}$ & $\begin{array}{r}-.5 \\
-.2 \\
.0 \\
2.1 \\
.1\end{array}$ & $\begin{array}{r}3.0 \\
.6 \\
1.4 \\
1.4 \\
.9\end{array}$ \\
\hline $\begin{array}{l}10 \\
11 \\
11 . B \\
12 \\
13\end{array}$ & $\begin{array}{rr}8 & 27 \\
9 & 5 \\
8 & 29 \\
8 & 21 \\
8 & 24\end{array}$ & $\begin{array}{r}74 \\
80 \\
84 \\
104 \\
109\end{array}$ & $\begin{array}{l}210 \\
150 \\
150 \\
180 \\
210\end{array}$ & $\begin{array}{r}12.4 \\
9.5 \\
9.9 \\
14.7 \\
18.1\end{array}$ & $\begin{array}{r}.16 \\
-.26\end{array}$ & $\begin{array}{r}.8 \\
1.9 \\
.2 \\
-.1 \\
.9\end{array}$ & $\begin{array}{r}10.8 \\
3.4 \\
.9\end{array}$ \\
\hline $\begin{array}{l}14 \\
15 \\
15 . B \\
16 \\
17\end{array}$ & $\begin{array}{ll}9 & 10 \\
8 & 11 \\
8 & 25 \\
8 & 31 \\
8 & 22\end{array}$ & $\begin{array}{l}110 \\
110 \\
114 \\
127 \\
138\end{array}$ & $\begin{array}{r}80 \\
150 \\
150 \\
135 \\
135\end{array}$ & $\begin{array}{r}6.8 \\
13.0 \\
13.5 \\
13.7 \\
15.0\end{array}$ & $\begin{array}{r}.40 \\
-.29 \\
-.51\end{array}$ & $\begin{array}{r}-.3 \\
.4 \\
-.1 \\
.4 \\
1.2\end{array}$ & $\begin{array}{r}2.2 \\
1.4 \\
11.1\end{array}$ \\
\hline $\begin{array}{l}18 \\
19 \\
19 . \mathrm{B} \\
20 \\
21\end{array}$ & $\begin{array}{lr}8 & 23 \\
8 & 26 \\
8 & 31 \\
9 & 4 \\
8 & 30\end{array}$ & $\begin{array}{l}151 \\
173 \\
174 \\
184 \\
208\end{array}$ & $\begin{array}{r}135 \\
100 \\
90 \\
125 \\
90\end{array}$ & $\begin{array}{l}16.2 \\
13.7 \\
12.5 \\
17.9 \\
14.8\end{array}$ & $\begin{array}{l}-.40 \\
-.32\end{array}$ & $\begin{array}{r}.5 \\
.4 \\
1.0 \\
.4 \\
.1\end{array}$ & $\begin{array}{r}1.6 \\
.4 \\
1.6 \\
.5\end{array}$ \\
\hline $\begin{array}{l}22 \\
23 \\
24 \\
25 \\
26\end{array}$ & $\begin{array}{rr}9 & 4 \\
9 & 13 \\
8 & 31 \\
9 & 11 \\
9 & 3\end{array}$ & $\begin{array}{l}216 \\
307 \\
310 \\
310 \\
318\end{array}$ & $\begin{array}{l}75 \\
75 \\
75 \\
60 \\
60\end{array}$ & $\begin{array}{l}12.6 \\
18.0 \\
18.3 \\
14.5 \\
14.7\end{array}$ & $\begin{array}{c}\mathrm{T} \\
\mathrm{T} \\
-.37 \\
.25 \\
-.53\end{array}$ & $\begin{array}{r}.4 \\
-.1 \\
-.1 \\
-.3 \\
-.2\end{array}$ & $\begin{array}{r}.8 \\
1.6 \\
.3 \\
.3 \\
1.0\end{array}$ \\
\hline $\begin{array}{l}27 \\
27 . B \\
28 \\
29 \\
30\end{array}$ & $\begin{array}{rr}9 & 12 \\
9 & 3 \\
9 & 3 \\
9 & 1 \\
9 & 9\end{array}$ & $\begin{array}{l}319 \\
338 \\
377 \\
393 \\
394\end{array}$ & $\begin{array}{l}60 \\
51 \\
52 \\
59 \\
40\end{array}$ & $\begin{array}{l}15.1 \\
13.5 \\
15.2 \\
18.3 \\
12.2\end{array}$ & $\begin{array}{r}.78 \\
-.52 \\
-.27 \\
-.20 \\
.52\end{array}$ & $\begin{array}{r}-.4 \\
.0 \\
1.3 \\
-.4 \\
.4\end{array}$ & $\begin{array}{r}.6 \\
28.3 \\
.5 \\
1.3 \\
2.4\end{array}$ \\
\hline $\begin{array}{l}31 \\
32 \\
33 \\
34\end{array}$ & $\begin{array}{rr}9 & 11 \\
9 & 13 \\
9 & 9 \\
9 & 2\end{array}$ & $\begin{array}{l}406 \\
418 \\
462 \\
464\end{array}$ & $\begin{array}{l}45 \\
44 \\
22 \\
40\end{array}$ & $\begin{array}{r}14.3 \\
14.3 \\
7.9 \\
14.5\end{array}$ & $\begin{array}{c}._{\mathrm{T}}^{57} \\
-.43 \\
-.45\end{array}$ & $\begin{array}{r}-.2 \\
-.7 \\
.0 \\
.2\end{array}$ & $\begin{array}{l}.8 \\
.8 \\
.7 \\
.6\end{array}$ \\
\hline $\begin{array}{l}35 \\
36 \\
37 \\
38\end{array}$ & $\begin{array}{rr}9 & 12 \\
9 & 12 \\
9 & 1 \\
9 & 3\end{array}$ & $\begin{array}{l}485 \\
486 \\
501 \\
612\end{array}$ & $\begin{array}{l}28 \\
38 \\
36 \\
34\end{array}$ & $\begin{array}{l}10.6 \\
14.5 \\
14.2 \\
16.2\end{array}$ & $\begin{array}{c}\mathrm{T}^{.53} \\
-.26\end{array}$ & $\begin{array}{r}.4 \\
.0 \\
-.5 \\
-.2\end{array}$ & $\begin{array}{l}.7 \\
1.6 \\
1.3 \\
5.5\end{array}$ \\
\hline
\end{tabular}

Columns 4 and 5 give the duration of the run and the approximate value of the fall of the holder. Since the absolute error of a determination of the height does not depend on the magnitude of the preceding or following fall of the holder, the percentage error of $\left(H_{1}-H_{2}\right)$ is 
likely to be less for large than for small falls; but on the other hand, in a run of the long duration needed for a large fall at a low rate, the outside temperature may change enough to make the temperature control inadequate and the mean temperature uncertain, so that very long runs are undesirable. It thus appears that a smaller holder would have been more suitable for measuring the lower rates of flow and that higher accuracy in the results is to be expected at the higher rates of flow than at the lower.

In column $6, \epsilon$ denotes the difference between the two mean values of the fall $\left(\mathrm{H}_{1}-\mathrm{H}_{2}\right)$ found from the measurements at the two pairs of stations at the ends of two perpendicular diameters of the holder; and $100 \epsilon /\left(H_{1}-H_{2}\right)$ is the percentage difference between the two estimates of $\left(H_{1}-H_{2}\right)$. Where no value is given, only one pair of measurements was available; the letter $\mathrm{T}$ indicates that they were made by observation of the tapes at stations 1 and 3 , and a blank means that they were made with the dial mechanisms at stations 2 and 4 . If all the measurements were accurate, these accidental differences would vanish and, on the whole, the smaller the discrepancy between the two values of $\left(H_{1}-H_{2}\right)$ the nearer their average is likely to be to the true value.

Column 7 gives the change of the observed mean temperature in the holder during the run. In 15 of the 43 cases the temperature rose a little, but it does not seem probable that there was ever any serious deficiency of saturation.

The number's in column 8 serve as a criterion for estimating the constancy of the rate of flow in those runs in which an orifice was under test; they are to be interpreted as follows: The observed values of the differential $\Delta$ across the orifice were averaged for each of the periods into which the run was subdivided, usually 5 in number, and the difference between the highest and lowest of these averages is denoted by $\delta \Delta$. The percentage difference, $100 \delta \Delta / \Delta$, is a measure of the inconstancy of the differential, aside from the more rapid fluctuations occurring within each period, and the accompanying variations of the rate of flow are about half as large as those of the differential.

It will be noticed that the variations were large in runs $0 . B$, 10,16 , and 27.B, and data on the Venturi or an orifice obtained in these runs must be regarded as of no value.

Where no figure is given in column 8, the rotary displacement ineter was under test, and constancy of the rate of flow is less important for this than for the Venturi or an orifice.

In the case of run 7 , the data on the holder are somewhat uncertain, the records not being clear, so that results from this run are also to be looked on with suspicion.

\section{RESULTS OF TESTS OF THE ROTARY DISPLACEMENT ME'TER}

The results of the eight experiments in which air from the holder was discharged through the rotary displacement meter are exhibited in Table 13, in which the third column gives the values found for the correction factor or coefficient $C_{d}$. The mean value 0.994 indicates that, on the average, the meter ran 0.6 per' cent fast in comparison with the holder. The departures of the individual values from the mean are shown in the last column; they average \pm 0.4 per cent and do not appear to be systematically related to the rate of flow, given in the second column, or to the duration of the run or the fall of the holder, given in columns 4 and 5 of Table 12. 
TABLE 13.-Rotary displacement meter

\begin{tabular}{|c|r|r|r|}
\hline $\begin{array}{c}\text { Number } \\
\text { of run }\end{array}$ & $\begin{array}{r}\text { Rate } \\
\frac{Q_{\boldsymbol{s}}}{1,000}\end{array}$ & \multicolumn{1}{|c|}{$\boldsymbol{C}_{\boldsymbol{d}}$} & $\boldsymbol{C}_{\boldsymbol{d}}-0.994$ \\
\cline { 1 - 2 } & 33 & 0.990 & -0.004 \\
12 & 104 & .996 & .002 \\
13 & 109 & 1.001 & .007 \\
15 & 110 & .985 & -.009 \\
$15 . \mathrm{B}$ & 114 & .995 & .001 \\
17 & 138 & .997 & .003 \\
18 & 158 & .999 & .005 \\
19 & 173 & .992 & -.002 \\
\hline & & .994 & \pm .004 \\
\hline
\end{tabular}

Table 14 contains the same results arranged chronologically, together with the temperature, $t^{\circ} \mathrm{F}$, of the air entering the meter (column 4); its absolute static pressure, $p$, in inches of mercury (column 5); and the approximate value of the pressure drop $\Delta p$ across the meter, in inches of water (column 6).

TABLe 14

\begin{tabular}{|c|c|c|c|c|c|}
\hline $\begin{array}{c}\text { Number } \\
\text { of run }\end{array}$ & $\begin{array}{c}\text { Date, } \\
\text { Septem- } \\
\text { ber, 1924 }\end{array}$ & $C_{\mathbf{d}}$ & $\boldsymbol{t}$ & $\begin{array}{c}p \\
\text { (in Hg) }\end{array}$ & $\begin{array}{c}\Delta p \\
\text { (in Hg) }\end{array}$ \\
\hline $\mathbf{1}$ & $\mathbf{2}$ & $\mathbf{3}$ & $\mathbf{4}$ & $\mathbf{5}$ & $\mathbf{6}$ \\
\hline & & & $\circ \mathrm{F}$. & & \\
15 & 11 & 0.985 & 69.3 & 29.46 & 0.45 \\
3 & 20 & .990 & 66.7 & 29.30 & .2 \\
12 & 21 & .996 & 66.5 & 29.34 & .4 \\
17 & 22 & .997 & 74.8 & 29.26 & \\
18 & 23 & .999 & 71.4 & 29.50 & 1.0 \\
13 & 24 & 1.001 & 71.4 & 29.32 & .55 \\
$15 . \mathrm{B}$ & 25 & .996 & 70.1 & 29.39 & .72 \\
19 & 26 & .992 & 70.7 & 29.35 & 1.23 \\
\hline
\end{tabular}

There is no systematic relation between the variations of $C_{d}$ and those of $t, p$, and $\Delta p$, but there seems to be a distinct run with the date, as given in column 2 , the values of $C_{d}$ increasing from the eleventh to the twenty-fourth of August, and decreasing on the two following days.

If this apparent connection between the value of $C_{d}$ and the time when it was measured were real, it would indicate either a systematic change in the operation of the meter or a contrary change in the operations of measuring the outflow from the holder. If the change of $C_{d}$ were simply progressive and always in the same direction, some interpretation might suggest itself, but we are inclined to regard the apparent connection as purely fortuitous.

If the measurements of rate of flow by the holder could be regarded as exact, the departures given in column 4 of Table 13 would have to be regarded as accidental errors of the rotary meter due to irregular running. But it seems much more likely that the apparent departures of $C_{d}$ from its mean value represent, at least in the main, accidental errors in determining the rate of flow by means of the holder. 


\section{RESULTS OF THE TESTS OF THE VENTURI METER}

The results of the tests of the Venturi meter are summarized in Table 15. Column 3 gives the approximate average value of the differential throughout the run, expressed in inches of water; column 4 gives it as a percentage of the absolute static pressure at the entrance to the Venturi; column 5 gives the value of the Reynolds number referred to the diameter and speed at the throat, as defined in note $\mathrm{B}$; column 6 gives the values of $C$, the hydraulic discharge coefficient based on the upstream density and with the approach factor included; column 7 gives the corresponding values of the adiabatic coefficient $C_{a}$ found from those of $C$ by means of equation (15); and column 8 gives the departures of the separate values of $C_{a}$ from the mean value of 0.990 .

TABLE 15.-Tests of the Venturi meter

\begin{tabular}{|c|c|c|c|c|c|c|c|}
\hline $\begin{array}{c}\text { Number } \\
\text { of run }\end{array}$ & $\begin{array}{l}\text { Rate } \\
\frac{Q_{s}}{1,000}\end{array}$ & (in. $\stackrel{\Delta}{\mathrm{H}}_{2} \mathrm{O}$ ) & $100 x$ & $\frac{R_{d}}{100,000}$ & $C$ & $C_{a}$ & $C_{a}-0.990$ \\
\hline 1 & 2 & 3 & 4 & 5 & 6 & $\boldsymbol{\gamma}$ & 8 \\
\hline $\begin{array}{l}19 \\
19 . \mathrm{B} \\
20 \\
21 \\
22\end{array}$ & $\begin{array}{l}173 \\
174 \\
184 \\
208 \\
216\end{array}$ & $\begin{array}{l}0.83 \\
0.91 \\
0.95 \\
1.07 \\
1.28\end{array}$ & & & $\begin{array}{l}1.051 \\
0.996 \\
1.018 \\
1.089 \\
1.024\end{array}$ & & \\
\hline $\begin{array}{l}23 \\
24 \\
25 \\
26\end{array}$ & $\begin{array}{l}307 \\
310 \\
310 \\
318\end{array}$ & $\begin{array}{l}2.76 \\
2.88 \\
2.82 \\
2.96\end{array}$ & $\begin{array}{l}0.69 \\
0.73 \\
0.70 \\
0.74\end{array}$ & $\begin{array}{l}6.6 \\
6.6 \\
6.6 \\
6.8\end{array}$ & $\begin{array}{l}1.016 \\
1.012 \\
1.012 \\
1.010\end{array}$ & $\begin{array}{r}0.992 \\
.988 \\
.988 \\
.987\end{array}$ & $\begin{array}{r}0.002 \\
-2 \\
-2 \\
-3\end{array}$ \\
\hline $\begin{array}{l}27 \\
28 \\
29 \\
30\end{array}$ & $\begin{array}{l}319 \\
377 \\
393 \\
394\end{array}$ & $\begin{array}{l}2.98 \\
4.24 \\
4.66 \\
4.56\end{array}$ & $\begin{array}{l}0.75 \\
1.04 \\
1.16 \\
1.13\end{array}$ & $\begin{array}{l}6.8 \\
8.0 \\
8.3 \\
8.4\end{array}$ & $\begin{array}{l}1.021 \\
1.011 \\
1.009 \\
1.012\end{array}$ & $\begin{array}{r}.997 \\
.987 \\
.988 \\
.991\end{array}$ & $\begin{array}{r}7 \\
-3 \\
-2 \\
1\end{array}$ \\
\hline $\begin{array}{l}31 \\
32 \\
33 \\
34\end{array}$ & $\begin{array}{l}406 \\
418 \\
462 \\
464\end{array}$ & $\begin{array}{l}4.95 \\
5.10 \\
6.25 \\
6.44\end{array}$ & $\begin{array}{l}1.23 \\
1.27 \\
1.54 \\
1.59\end{array}$ & $\begin{array}{l}8.6 \\
9.2 \\
9.9 \\
9.9\end{array}$ & $\begin{array}{l}1.010 \\
1.015 \\
1.006 \\
1.005\end{array}$ & $\begin{array}{r}.989 \\
.994 \\
.988 \\
.986\end{array}$ & $\begin{array}{r}-1 \\
4 \\
-2 \\
-4\end{array}$ \\
\hline $\begin{array}{l}35 \\
36 \\
37 \\
38\end{array}$ & $\begin{array}{l}485 \\
486 \\
501 \\
611\end{array}$ & $\begin{array}{r}7.05 \\
7.04 \\
7.58 \\
11.25\end{array}$ & $\begin{array}{l}1.75 \\
1.75 \\
1.87 \\
2.76\end{array}$ & $\begin{array}{l}10.6 \\
10.4 \\
10.3 \\
12.9\end{array}$ & $\begin{array}{l}1.004 \\
1.011 \\
1.004 \\
1.005\end{array}$ & $\begin{array}{r}.987 \\
.903 \\
.987 \\
.993\end{array}$ & $\begin{array}{r}-3 \\
3 \\
-3 \\
3\end{array}$ \\
\hline Means. & & & & 8.7 & & 0.990 & \pm 0.003 \\
\hline
\end{tabular}

In runs 19 to 22 the differential was too low to be measured at all accurately, as is evident from the large irregular variations of $C$; and 13 further values from tests at rates of flow below 130,000 cubic feet per hour varied still more. The Venturi was, in fact, too large to be used satisfactorily at rates below about 300,000 cubic feet per hour, under working conditions which did not permit of keeping the flow absolutely steady, and we shall therefore ignore all these runs up to No. 22 and confine our attention to those from No. 23 onward.

Run 27.B is also omitted from the tabulation because the rate of flow was very far from constant, as shown in column 8 of Table 12: it gave $C=0.665$.

The mean of the remaining 16 values of $C_{\mathrm{a}}$ is 0.9897 . The departures of the separate values from 0.990 are given in column 8: they 
average a little less than \pm 0.003 and do not show any systematic variation with the rate of flow.

It will be noticed that 9 of the 16 values lie within the limits 0.987 to 0.989 and this makes it appear probable that if there had been a much larger number of experiments the mean would have been a little lower than 0.990 . There are also other indications pointing in this direction.

In run 27 , which gives the greatest departure from the mean, there was also the greatest discrepancy between the mean values of $\left(H_{1}-\right.$ $\mathrm{H}_{2}$ ) for the two pairs of measuring stations at the holder. (See Table 12.) Furthermore, the discharge coefficient of the 20 per cent orifice, which was measured during this run, also came out higher than would be expected from comparison with neighboring values, so that it seems probable that the error of the holder measurement in this run was rather larger than usual. The value for run 38 is also under suspicion because the rate of flow was much more variable than in the other runs listed in Table 15. (See Table 12 column 8.)

There is no obviously valid principle for assigning weights to the various values, but if we omit runs 27 and 38 altogether, the remaining 14 values give a mean of 0.9889 with a mean departure from the mean of \pm 0.002 .

If we further confine our attention to those runs in which there were height measurements at all four stations and the agreement of the two means was as good as or better than the average, we have Nos. 24, 25, 28, and 29, for which the values of $C_{\mathrm{a}}$ are 0.988, 0.988, 0.987 , and 0.988 .

Thus everything points to the conclusion that the mean value 0.990 , obtained by treating all the 16 values as of equal weight, is a little high, and we shall adopt the value $C_{a}=0.989$ as being probably as close to the truth as can be got from these experiments.

The accidental variations of $C_{a}$ shown in column 8 of Table 15 are the joint results of errors in the measurements at the holder and errors in the observations at the Venturi, especially in the measurement of the differential. It is impossible to separate the two kinds of error so as to estimate their relative importance, but it seems safe to conclude that neither kind of error was often greater than \pm 0.3 per cent.

\section{DISCUSSION OF THE RESULTS OBTAINED WITH THE VENTURI}

A discharge coefficient is, by definition, the ratio of an observed rate of flow to a "theoretical" rate. In computing the theoretical rate of flow of a liquid through a Venturi, the density is treated as constant. In computing the theoretical rate of flow of a gas, by the thermodynamic method which leads to the definition of the adiabatic discharge coefficient $C_{a}$, the variation of density accompanying the change of pressure from entrance to throat is taken account of in the equations, by the aid of certain assumptions which are known to be very nearly true and need not detain us here. In both cases, the dissipation of energy by turbulence and skin friction is ignored, and the unavoidable presence of dissipation in any real experiment is the main reason for the failure of the theory, in either case, to represent the observed facts exactly. 
Now the dissipation is due almost exclusively to the existence of viscosity; and the effect of viscosity on the nature of the motion of a fluid through a Venturi is fixed by the value of the Reynolds number. Hence we conclude that if a Venturi is tested with both air and water at the same value of the Reynolds number, the value of $C_{a}$ found in the experiment on air should be very nearly identical with the coefficient $C_{w}=C / \sqrt{1-\beta^{4}}$, or the discharge coefficient with the approach factor not included, found in the experiment on water.

The particular Venturi now in question was tested only with air, but it is of some interest to compare the results with those of previous tests of similar Venturis with water; and for this purpose we may use a curve constructed by one of the present authors ${ }^{4}$ in 1921, from the rather scanty published data then available regarding the discharge coefficients of Venturis for water. The curve, which represents $C_{20}$ as a function of $\log R_{d}$, is reproduced on a small scale in the Report of the A. S. M. E. Special Research Committee on Fluid Meters, 3d ed., p. 67, 1931; and the statement is there made that: "The curve represents the general run of the values of $C$ (denoted here by $C_{w}$ ), and it seems likely that values read from it will always be accurate within 1 per cent."

In the present instance, the mean value of $R_{d}$ was 870,000 (Table 15 , column 5) and at this point the reading from the curve is $C_{w}=0.9874$ as compared with our mean value $C_{a}=0.990$ or the more probable value 0.989 .

At the limiting values $R_{d}=660,000$ and $1,290,000$, the curve gives $C_{w}=0.9864$ and 0.9887 ; and in view of the accidental errors shown by column 8 of Table 15, it is not surprising that our values of $C_{a}$ should fail to show any evidence of systematic variation with the rate of flow.

\section{DISCHARGE COEFFICIENTS OF THE ORIFICES}

Only the four smallest orifices were tested against the holder, and the results obtained are collected in Tables 16 and 17 . They are given as values of "the hydraulic discharge coefficient based on the upstream density with the approach factor included"; that is, values of $C$ computed by means of equation (14) of Section X, 5 .

The differential, in per cent of the upstream absolute static pressure, is given as $100 x$. Since one atmosphere is equivalent to about 1,030 $\mathrm{cm}$. of water and the static pressure was never far from atmospheric, the differentials, as actually measured in centimeters of water, were about ten times the values given for $100 x$. If expressed in inches of water, they would be about four times the values of $100 x$.

Values of $C$ from runs $0 . B, 10,16$, and 27.B are omitted as worthless because the rate of flow was very inconstant. (See Table 12, column 8.) A value from run 7 is also omitted because the records of the measurements on the holder are not clear.

The three values in parentheses are also to be disregarded-in run 1 , because there was evidently some mistake of recording, though it could not be found and corrected; and in runs 11 and $15 . \mathrm{B}$, because the differential (about 0.8 inch) was too small for accurate measurement.

4E. Buckingham. 
In order to compare the remaining values of $C$ with the results of other observers, further computations are necessary but they will not be given till a later section.

TABLE 16.-Discharge coefficients of 5 and 10 per cent orifices

\begin{tabular}{|c|c|c|c|c|c|}
\hline \multirow{2}{*}{ Run } & \multirow{2}{*}{$\frac{\begin{array}{c}\text { Rate } \\
1,000 \mathrm{cu} . \mathrm{ft} .\end{array}}{\text { hour }}$} & \multicolumn{2}{|c|}{5 per cent } & \multicolumn{2}{|c|}{10 per cent } \\
\hline & & $C$ & $100 x$ & $C$ & $100 x$ \\
\hline $\begin{array}{l}1 \\
2 \\
4 \\
5\end{array}$ & $\begin{array}{l}34 \\
35 \\
40 \\
52\end{array}$ & $\begin{array}{c}(0.366) \\
.582 \\
.589\end{array}$ & $\begin{array}{r}1.85 \\
.76 \\
.93\end{array}$ & 0.597 & 0.38 \\
\hline $\begin{array}{c}6 \\
8 \\
9 \\
11 \mathrm{~B} \\
14\end{array}$ & $\begin{array}{r}55 \\
62 \\
72 \\
84 \\
110\end{array}$ & $\begin{array}{l}.600 \\
.601 \\
.602 \\
.591\end{array}$ & $\begin{array}{l}\text { 1. } 65 \\
\text { 2. } 03 \\
\text { 2. } 69 \\
\text { 3. } 95\end{array}$ & .597 & 1.59 \\
\hline
\end{tabular}

TABLE 17.-Discharge coefficients of 20 and 30 per cent orifices

\begin{tabular}{|c|c|c|c|c|c|}
\hline \multirow{2}{*}{ Run } & \multirow{2}{*}{$\frac{\begin{array}{c}\text { Rate } \\
1,000 \mathrm{cu} . \mathrm{ft} .\end{array}}{\text { hour }}$} & \multicolumn{2}{|c|}{20 per cent } & \multicolumn{2}{|c|}{30 per cent } \\
\hline & & $C$ & $100 x$ & $C$ & $100 x$ \\
\hline $\begin{array}{l}11 \\
15 \mathrm{~B} \\
19 \\
19 \mathrm{~B}\end{array}$ & $\begin{array}{r}81 \\
114 \\
174 \\
175\end{array}$ & $\begin{array}{c}(0.632) \\
.605 \\
.610\end{array}$ & $\begin{array}{l}0.21 \\
1.07 \\
1.00\end{array}$ & $(0.628)$ & 0.19 \\
\hline $\begin{array}{l}20 \\
21 \\
22 \\
23\end{array}$ & $\begin{array}{l}184 \\
209 \\
216 \\
307\end{array}$ & $\begin{array}{l}.614 \\
.610 \\
.617\end{array}$ & $\begin{array}{l}1.07 \\
1.38 \\
1.42\end{array}$ & .633 & 1.34 \\
\hline $\begin{array}{l}24 \\
25 \\
26 \\
27\end{array}$ & $\begin{array}{l}311 \\
311 \\
319 \\
320\end{array}$ & $\begin{array}{l}.608 \\
.609 \\
.608 \\
.612\end{array}$ & $\begin{array}{l}3.27 \\
3.22 \\
3.35 \\
3.43\end{array}$ & & 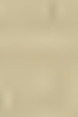 \\
\hline $\begin{array}{l}28 \\
29 \\
30 \\
31\end{array}$ & $\begin{array}{l}378 \\
395 \\
396 \\
407\end{array}$ & $\begin{array}{l}.604 \\
.603 \\
.606 \\
.605\end{array}$ & $\begin{array}{l}4.68 \\
5.17 \\
5.07 \\
5.47\end{array}$ & & \\
\hline $\begin{array}{l}32 \\
33 \\
34 \\
35\end{array}$ & $\begin{array}{l}418 \\
463 \\
466 \\
485\end{array}$ & & & $\begin{array}{l}.633 \\
.630 \\
.629 \\
.628\end{array}$ & $\begin{array}{l}2.43 \\
2.91 \\
2.99 \\
3.29\end{array}$ \\
\hline $\begin{array}{l}36 \\
37 \\
38\end{array}$ & $\begin{array}{l}488 \\
503 \\
614\end{array}$ & & & $\begin{array}{l}.630 \\
.618 \\
.627\end{array}$ & $\begin{array}{l}3.32 \\
3.49 \\
5.05\end{array}$ \\
\hline
\end{tabular}

\section{COMPARISON OF THE ORIFICES WITH THE VENTURI}

The time during which the holder was available for experimental work was not long enough for making absolute tests of all the orifices, so a more expeditious method had to be adopted. It consisted in running air though an orifice and the Venturi in series and treating the Venturi as a secondary standard, its discharge coefficient having been determined in the tests against the holder.

$$
60869-31-9
$$




\section{EXPERIMENTAL PROCEDURE}

The intake of the booster was disconnected from the holder and left open so that air from outside could be forced into the line, and the rotary displacement and wet drum meters were by-passed, to avoid pulsations in the flow. The orifice to be tested was put in position; a pair of the water manometers was connected to the pressure taps 12 inches upstream and 6 inches downstream; and a second pair was connected to the entrance and throat piezometer rings of the Venturi.

After these preliminaries, the booster was started and brought up to a constant speed; and as soon as a steady state had been established, with the water columns as nearly at rest as could be hoped for, the manometers were shut off simultaneously. The wet and dry bulb temperatures and the pressures were then read and recorded, together with the barometric pressure.

These operations were repeated once or twice before changing the speed of the booster or going on to a different orifice, and the average of the results was treated as a single test or run.

\section{COMPUTATIONS}

Similar observations are made at the orifice and at the Venturi, and symbols that refer to the Venturi may be distinguished by subscript $v$. At the orifice, let:

$p=$ the absolute static pressure at the upstream tap;

$t=$ the dry bulb temperature;

$\rho=$ the density of the air at $p, t$;

$\Delta=$ the differential;

$d=$ the diameter of the orifice; and

$C=$ the hydraulic discharge coefficient, based on the upstream density and with the approach factor included.

Let the corresponding quantities for the Venturi be denoted by $p_{v}, t_{v}$, etc., $d_{v}$ being the diameter of the throat. The value of $C_{v}$ is assumed to be known from the holder experiments, and $C$ is the quantity sought.

When the flow is steady, it is the same at both places and we have

or

$$
C_{\frac{\pi}{4}}^{\pi} d^{2} \sqrt{2 \rho \Delta}=C_{v} \frac{\pi}{4} d_{v}^{2} \sqrt{2 \rho_{v} \Delta_{v}}
$$

$$
C=C_{v}\left(\frac{d_{v}}{d}\right)^{2} \sqrt{\frac{\rho_{v} \Delta_{v}}{\rho \Delta}}
$$

The diameters, $d$ and $d_{v}$, have been measured, once for all. The observed differentials, $\Delta$ and $\Delta_{v}$, appear only in a ratio so that with the manometers all at nearly the same temperature, no reduction to standard temperature is needed.

The ratio of the densities is found by means of the equation

$$
\frac{p}{\rho T}=\text { constant }
$$

This would not be permissible if the vapor content of the air varied between the orifice and the Venturi; but the psychrometers showed 
that the air was always less than saturated, so that condensation was impossible; and, on the other hand, no water could be taken up because the line was dry; the composition of the mixture was therefore constant.

Upon setting $T=(458+t)$ in equation (21) (see Section $\mathrm{X}, 3$ ) we now have

$$
\frac{\rho_{v}}{\rho}=\frac{p_{v}(458+t)}{p\left(458+t_{v}\right)}
$$

and it remains only to consider the value of $C_{v}$.

Assuming the constant mean value $C_{a}=0.989$ obtained from the tests of the Venturi against the holder (Section XI, 3 ), we have by equation (15) (Section $\mathrm{X}, 6$ )

$$
C_{v}=0.989\left[\frac{3.5\left(r^{1,0}-r^{1,2}\right)}{(1-r)\left(1-\beta^{4} r^{1 r^{0}}\right)}\right]^{3 / 2}
$$

in which $\beta=0.4823$ is the diameter ratio of the Venturi and, in our present notation,

$$
r=\frac{p_{v}-\Delta_{v}}{p_{v}}
$$

with $p_{v}$ and $\Delta_{v}$ expressed in the same units.

Upon making these various substitutions in equation (20), we obtain the required value of $C$.

\section{RESULTS OF THE COMPARISONS}

In testing the smaller orifices, the differential was lower at the Venturi than at the orifice and with the large orifices this relation was inverted. In either case, the precision of the result was limited by the accuracy with which the smaller of the two differentials could be measured. There were, in all, 42 of these comparison tests, comprising 124 separate sets of readings, but those in which the smaller differential was less than $1.56 \mathrm{~cm}$ or 0.6 inch have been discarded as too unreliable to be worth reporting. The results of the remaining 26 runs are

\begin{tabular}{|c|c|c|c|c|c|c|c|c|c|}
\hline 1 & 2 & 3 & 4 & 5 & 1 & 2 & 3 & 4 & 5 \\
\hline Area ratio $\times 100$ & $\begin{array}{l}\text { Num- } \\
\text { ber of } \\
\text { run }\end{array}$ & $C$ & $100 x$ & $\begin{array}{l}\Delta \text { or } \Delta_{\dot{B}} \\
\mathrm{~cm} \mathrm{H} \mathrm{H}_{2} \mathrm{O}\end{array}$ & Area ratio $\times 100$ & $\begin{array}{l}\text { Num- } \\
\text { ber of } \\
\text { run }\end{array}$ & $C$ & $100 x$ & \begin{tabular}{|}
$\Delta$ or $\Delta$ \\
$\mathrm{cm} \mathrm{H} \mathrm{H}_{2} \mathrm{O}$
\end{tabular} \\
\hline $10 \ldots$ & $\begin{array}{l}10 \\
11 \\
12\end{array}$ & $\begin{array}{r}0.595 \\
.592 \\
.589\end{array}$ & $\begin{array}{l}2.98 \\
5.14 \\
5.74\end{array}$ & $\begin{array}{l}\text { 1. } 56 \\
\text { 2. } 77 \\
3.13\end{array}$ & 40 & $\left\{\begin{array}{l}30 \\
31\end{array}\right.$ & $\begin{array}{r}0.681 \\
.657 \\
\end{array}$ & $\begin{array}{l}0.62 \\
1.76\end{array}$ & $\begin{array}{r}6.42 \\
18.09\end{array}$ \\
\hline & $\begin{array}{l}13 \\
14\end{array}$ & $\begin{array}{l}.596 \\
.591\end{array}$ & $\begin{array}{l}6.91 \\
7.35\end{array}$ & $\begin{array}{l}3.91 \\
4.11\end{array}$ & 45 & $\begin{array}{l}32 \\
33\end{array}$ & $\begin{array}{r}.681 \\
.679\end{array}$ & $\begin{array}{r}.67 \\
1.73\end{array}$ & $\begin{array}{r}6.94 \\
18.46\end{array}$ \\
\hline $20 \ldots$ & $\begin{array}{l}22 \\
23 \\
24\end{array}$ & $\begin{array}{l}.609 \\
.608 \\
.601\end{array}$ & $\begin{array}{l}1.52 \\
3.03 \\
6.47\end{array}$ & $\begin{array}{r}3.25 \\
6.65 \\
14.90\end{array}$ & 50 & $\begin{array}{l}34 \\
35\end{array}$ & $\begin{array}{r}.706 \\
.702\end{array}$ & $\begin{array}{r}.38 \\
1.34\end{array}$ & $\begin{array}{r}4.01 \\
14.22\end{array}$ \\
\hline 30 & $\begin{array}{r}25 \\
26\end{array}$ & $\begin{array}{l}.632 \\
.629\end{array}$ & $\begin{array}{r}.90 \\
2.43\end{array}$ & $\begin{array}{r}4.64 \\
12.91\end{array}$ & & $\begin{array}{l}36 \\
37\end{array}$ & $\begin{array}{r}.728 \\
.729\end{array}$ & $\begin{array}{r}.37 \\
1.00\end{array}$ & $\begin{array}{r}3.85 \\
10.63\end{array}$ \\
\hline & 27 & .627 & 3. 51 & 19. 03 & 60 & $\begin{array}{r}38 \\
.30\end{array}$ & .760 & .79 & $\begin{array}{l}8.33 \\
7.01\end{array}$ \\
\hline 35 & $\begin{array}{l}28 \\
29\end{array}$ & $\begin{array}{c}(.464) \\
.640\end{array}$ & $\begin{array}{c}(2.03) \\
2.87\end{array}$ & $\begin{array}{l}(7.74) \\
22.02\end{array}$ & $\begin{array}{l}70- \\
755\end{array}$ & $\begin{array}{l}40 \\
41\end{array}$ & $\begin{array}{l}.827 \\
.909\end{array}$ & $\begin{array}{l}.51 \\
.39\end{array}$ & $\begin{array}{l}5.34 \\
4.13\end{array}$ \\
\hline & & & & & 80. & 42 & 1.005 & .28 & 2.95 \\
\hline
\end{tabular}
shown in Table 18.

TaBLe 18.-Orifices $v$. Venturi 
The first two columns give the area ratio of the orifice, in per cent, and the serial number of the run. The third and fourth columns show the values found for $C$ and the percentage differentials at which they were found. The last column gives the lower of the two differentials, expressed in centimeters of water, as measured.

In run 28 there was evidently a mistake in reading or recording the differential across the orifice, and the value of $C$ may be disregarded.

\section{DISCUSSION OF THE RESULTS OF THE EXPERI- MENTS ON ORIFICES}

Accurate standardization tests of a set of orifices are valuable to anyone who is to use these particular orifices for metering purposes. But however carefully the work may have been done, the results of a comparatively small number of tests, such as have been reported here, are of little general interest except as they confirm, correct, or extend the body of information about the discharge coefficients of orifices which is already publicly available. We have therefore to compare the discharge coefficients obtained in the present investigation with some of those already published by others.

In the present instance, the pipe was smooth and the orifices were carefully finished. Furthermore, the orifices were large, their diameters ranging from 5.2 inches upward, so that the remaining imperfections of the edges were very small relatively to the absolute sizes of the orifices. In the vital matter of geometrical shape, our apparatus was thus very closely comparable with the apparatus used by Witte ${ }^{5}$ in some of his admirable experiments with water, and our results will therefore be compared with his.

Before this comparison can be instituted, some preliminary reductions are needed; for although the similarity of shape of the apparatus appears satisfactory, the experimental conditions differed in two respects.

In the first place, the points where the pressures were measured were not similarly situated. In Witte's experiments, the pressure connections were made in the corners between the wall of the pipe and the faces of the orifice plate, whereas in the present experiments, the pressures were taken off at points 12 inches upstream and 6 inches downstream. To make the results comparable, this difference must be allowed for by utilizing the observations on the longitudinal distribution of pressure, described above in Section IX.

In the second place, the discharge coefficient of an orifice for a gas varies with the pressure ratio. Hence it is necessary to allow for this effect of changing density by extrapolating from values measured at various finite values of the fractional differential, $\Delta / p_{1}=x$, to find the limiting value at $x=0$, which represents what would have been obtained if the density had remained constant during the flow through the orifice, as it does with water.

\section{REDUCTION FOR CHANGE OF TAP LOCATION}

In a given test, let $\Delta^{\prime}$ be the observed differential, $\rho^{\prime}$ be the density at the observed upstream pressure, and $C^{\prime}$ be the discharge coefficient,

R. Witte, Durchflusszahlen von Düsen und Staurändern, Techn. Mech. u. 'Thermodynamik, 1 Nos. $1,2,3 ; 1930$. 
computed from $\Delta^{\prime}$ and $\rho^{\prime}$, together with the observed mass flow, $M$, and the known diameter, $d$. Let $\Delta^{\prime \prime}, \rho^{\prime \prime}$, and $C^{\prime \prime}$ be the values that would have been obtained in the same test if a different pair of taps had been employed. Then we have, by definition,

$$
M=C^{\prime} \frac{\pi}{4} d^{2} \sqrt{2 \rho^{\prime} \Delta^{\prime}}=C^{\prime \prime} \frac{\pi}{4} d^{2} \sqrt{2 \rho^{\prime \prime} \Delta^{\prime \prime}}
$$

or

$$
\frac{C^{\prime \prime}}{C^{\prime}}=\sqrt{\frac{\rho^{\prime} \Delta^{\prime}}{\rho^{\prime \prime} \Delta^{\prime \prime}}}
$$

Now the longitudinal variations of the upstream static pressure, within a few pipe diameters of the orifice, are, at most, only a few per cent of the drop through the orifice (see Tables 2 to 11); and in the present experiments, that drop was never as much as 8 per cent of the absolute static pressure. Hence the percentage difference of the two upstream static pressures was insignificant and for our present purposes equation (26) may be simplified to the form

$$
\frac{C^{\prime \prime}}{C^{\prime}}=\sqrt{\frac{\Delta^{\prime}}{\Delta^{\prime \prime}}}
$$

If the curve of pressure distribution, qualitatively illustrated in Figure 4, has been determined by experiment, the difference of pressure, $\Delta^{\prime}$, between two taps at any distances from the orifice plate within the range of the experiments may evidently be found, in terms of the difference between the upstream and downstream minima, by readings from the curve. The same is true of the differential $\Delta^{\prime \prime}$ between any second pair of taps, and we can thus find the ratio $\Delta^{\prime} / \Delta^{\prime \prime}$ for any two pairs of taps. This may then be substituted in equation (27) and if one of the two discharge coefficients has been determined, the other may be computed from it.

The observations did not cover a sufficient length of pipe to give any information about the arrangement commonly known as "pipe taps," in which the pressure connections are made at points $2.5 D$ upstream and $8 D$ downstream, $D$ being the pipe diameter; and our further considerations relate only to the region from $1 D$ upstream to $0.5 D$ downstream.

For this region, the composite data given in the final columns of Tables 2 to 11 were plotted against distances, as in Figures 5 and 6 , and smooth curves were drawn through the two sets of points, for each orifice. Values of $\Delta^{\prime} / \Delta$ were read from the curves at several pairs of distances, the values for each pair were plotted against the area ratios of the orifices, and a second set of smooth curves was drawn. The two sets of curves were then readjusted until they appeared to give a representation of the observed facts which was as free as practicable from the influence of accidental errors of measurement.

Values of the reduction factor $\sqrt{\Delta^{\prime} / \Delta^{\prime \prime}}$, required for use with equation (27), were obtained from these adjusted curves and the results are exhibited in Table 19, in which the notation is as follows:

$C(12,6)$ represents the value of the hydraulic discharge coefficient, based on the upstream density and with the approach factor included, as observed with the pressure taps 12 inches upstream and 6 inches downstream from the orifice. 
$C(24,12)$ is the value that would have been found if the distances had been 24 inches and 12 inches, or approximately $1 \mathrm{D}$ and $0.5 \mathrm{D}$; this combination has been called "throat taps."

$C(3,3)$ is the value that would have been found with the taps 3 inches or $D / 8$ on each side of the orifice plate; this corresponds to the "flange taps" in B. S. Research Paper No. $49{ }^{6}$

$C(1,1)$ is the value that would have been obtained if the taps had been 1 inch from the orifice plate; since we had no taps that were less than 1 inch, or $D / 24$, from the orifice plate, this arrangement was the nearest we had to taking off the pressures right in the corner.

It may be noted that the values in Table 19 were obtained from the composite values in Tables 2 to 11, and that each one should not, in reality, be quite constant, because the pressure distribution curves varied with the rate of flow, as was illustrated by Figure 5. But over the length of pipe now in question, and over the range of differentials for which the reduction factors in Table 19 have been deduced, these variations are small and probably altogether insignificant in comparison with other unavoidable errors.

\section{ALLOWANCE FOR VARYING DENSITY; THE EXPANSION FACTOR}

Let us suppose that an orifice is tested with a liquid, and let $K$ denote the discharge coefficient with the approach factor included, defined in terms of normal units by the equation

$$
M=K \frac{\pi}{4} d^{2} \sqrt{2 \rho \Delta}
$$

in which $M, d, \rho$, and $\Delta$ have their usual meanings, but $\rho$ does not require any identifying subscript because it is sensibly constant for any one liquid.

At low values of the Reynolds Number (small orifice, low speed, high viscosity) $K$ varies with the rate of flow; but at high values, where the effects of viscosity are negligible, the value of $K$ is constant and no longer dependent on the rate of flow.

If the same orifice is tested with a gas, such as air, we have (see equation 12 , Section $\mathrm{X}, 5$ )

$$
M=C \frac{\pi}{4} d^{2} \sqrt{2 \rho_{1} \Delta}
$$

but even though the Reynolds Number be so high as to make viscosity of no importance, $C$ is not constant but decreases as the differential and the rate of flow are increased.

TABLE 19.-Reduction factors for change of tap location

\begin{tabular}{|r|r|r|r|}
\hline $\begin{array}{c}\text { Area } \\
\text { ratio } \beta^{2}\end{array}$ & $\frac{C(24.12)}{C(12,6)}$ & $\frac{C(3,3)}{C(12,6)}$ & $\frac{C(1,1)}{C(12,6)}$ \\
\hline 0.05 & 0.999 & 1.000 & 1.001 \\
.10 & .999 & 1.000 & 1.001 \\
.20 & .999 & .999 & 1.000 \\
.30 & .998 & .997 & .999 \\
.35 & .998 & .996 & .998 \\
.40 & .998 & .994 & .997 \\
.45 & .999 & .992 & .995 \\
.50 & 1.000 & .989 & .991 \\
.55 & 1.002 & .986 & .987 \\
.60 & 1.005 & .982 & .981 \\
.65 & 1.012 & .976 & .975 \\
\hline
\end{tabular}

- See footnote 3, p. 119. 
If tests are carried out over a sufficient range of values of the fractional differential, $\Delta / p_{1}=x$ (but all at high values of the Reynolds Number, where the effects of viscosity are insensible, as was true of all the tests recorded here), the results show that as $x$ decreases, the values of $C$ tend toward the fixed value $K$ as a limit. It is therefore convenient to represent $C$ in the form

$$
C=K Y
$$

in which $K$ is the constant discharge coefficient found by testing the orifice with water, and $Y$ is the variable "expansion factor," introduced into the literature by E. S. Smith ${ }^{7}$ to take account of the effect of the variations of density during flow through an orifice, which occur with a gas but are absent in the simpler case of a liquid.

The experiments described in this paper did not cover a sufficient range of values of $x$ to permit of determining the form of $Y$, but we may utilize later information obtained from experiments on natural gas, conducted at Los Angeles in 1929 by one of us, ${ }^{8}$ as part of an investigation being carried out by a committee of the natural gas department of the American Gas Association, in cooperation with the National Bureau of Standards.

Similar information is contained in B. S. Research Paper No. $49^{9}$ but the Los Angeles results are to be preferred, because the working conditions were more favorable as regards steadiness of flow and permitted of higher precision in the measurements.

In the Los Angeles experiments, the orifices were tested in new commerical steel pipes of 16,8 , and 4 inch nominal diameter, with honeycombs of smaller pipes placed from $10 D$ to $15 D$ ahead of the orifices; and pressure measurements were made at taps distant 1 inch from the orifice plates.

So far as concerns the expansion factor, the results of the tests in the 16 and 8 inch pipes were consistent, and the change of relative tap distance from $D / 16$ to $D / 8$ made no appreciable difference: but the further change to $D / 4$ did appear to have a slight effect, and we shall confine our attention to the tests in the two larger pipes. These were carried out on 17 orifices with diameter ratios from 0.124 to 0.869 , or area ratios between 1.5 and 76 per cent.

When the values of $C$ for each orifice were plotted against the values of $x$ at which they were measured, the result was a diagram, such as is illustrated, qualitatively, by Figure 7 .

For the two orifices with diameter ratios below $\beta=0.2$ the curves were sligltly convex upward, but for the remaining 15 , for which 0.3 $<\beta<0.87$, the series of plotted points showed no evidence of systematic departure from straight lines. The expansion factor was therefore of the form

$$
Y=1-B x
$$

with $B$ a constant for each orifice but increasing with $\beta$.

Table 20 gives the diameter ratios, the number of tests on each orifice, and the range of values of $x$ over which the tests were distributed.

"Ed S. Smith, jr., "Quantity-Rate Fluid Meters," paper presented at the annual meeting of the A. S. M. E., New York, December, 1929. Trans. A. S. N. E. paper No. HYD-52-7b, 52, No. 30.

H. S. Bean.

- See footnote 3, p. 119. 
Table 20.-Los Angeles tests

\begin{tabular}{|c|c|c|c|c|}
\hline \multirow{2}{*}{$\begin{array}{c}\text { Pipe } \\
\text { diameter } \\
D \\
\text { (inches) }\end{array}$} & \multirow{2}{*}{$\begin{array}{c}\text { Diameter } \\
\text { ratio } \\
\boldsymbol{\beta}\end{array}$} & \multirow{2}{*}{$\begin{array}{c}\text { Number } \\
\text { of tests }\end{array}$} & \multicolumn{2}{|c|}{$x$} \\
\hline & & & $\begin{array}{l}\text { Mini- } \\
\text { mum }\end{array}$ & $\begin{array}{l}\text { Maxi- } \\
\text { mum }\end{array}$ \\
\hline & $\begin{array}{r}0.390 \\
.553 \\
.650 \\
.693\end{array}$ & $\begin{array}{l}26 \\
27 \\
21 \\
21\end{array}$ & $\begin{array}{l}0.009 \\
.010 \\
.007 \\
.006\end{array}$ & $\begin{array}{r}0.46 \\
.40 \\
.26 \\
.20\end{array}$ \\
\hline 10.00 & $\begin{array}{l}.748 \\
.796 \\
.823 \\
.861\end{array}$ & $\begin{array}{l}14 \\
11 \\
18 \\
11\end{array}$ & $\begin{array}{l}.009 \\
.014 \\
.02 \\
.02\end{array}$ & $\begin{array}{l}.13 \\
.11 \\
.08 \\
.06\end{array}$ \\
\hline 8.05 & $\begin{array}{l}.310 \\
.497 \\
.621 \\
.683 \\
.745 \\
.807 \\
.869\end{array}$ & $\begin{array}{l}21 \\
21 \\
21 \\
28 \\
29 \\
31 \\
29\end{array}$ & $\begin{array}{l}.03 \\
.02 \\
.02 \\
.02 \\
.02 \\
.02 \\
.02\end{array}$ & $\begin{array}{l}.51 \\
.53 \\
.57 \\
.65\end{array}$ \\
\hline
\end{tabular}

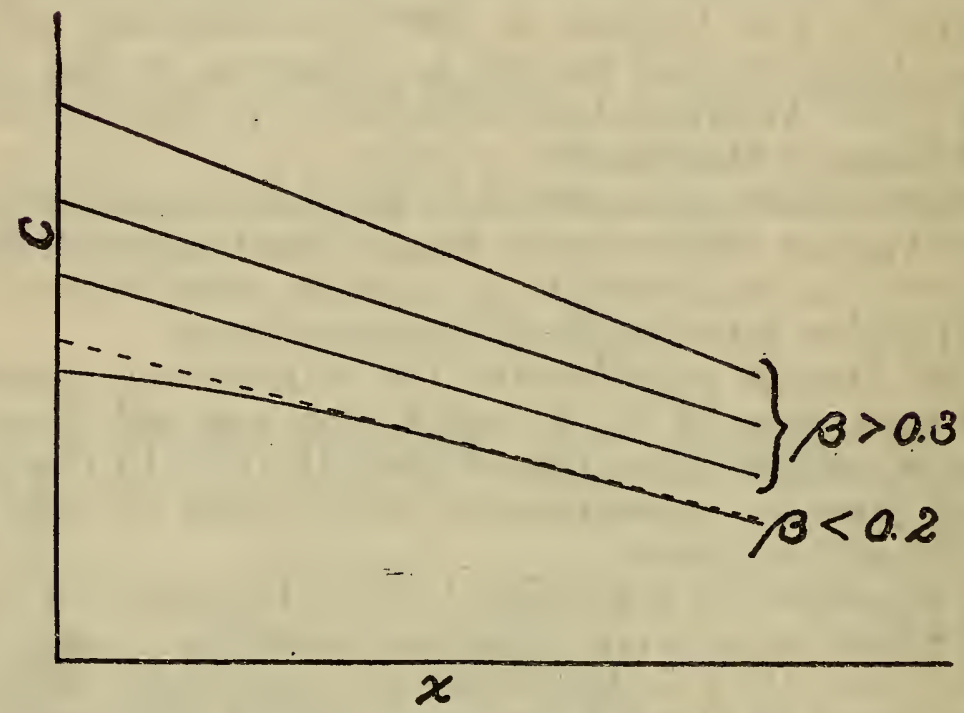

Figure 7.-Qualitative relation between the discharge coefficient $C$ and the differential-static pressure ratio $x$

The slopes of all the 15 straight lines obtained from these tests may be represented, within the precision of the measurements, by setting

$$
Y=1-\left(0.31+0.35 \beta^{4}\right) x
$$

but this equation is not directly applicable to experiments on air; for the expansion factor depends on the specific heat ratio, $C_{p} / C_{V}=\gamma$, as well as on $x$, according to some equation

$$
Y=f(x, \gamma)
$$

and the specific heat ratio of the Los Angeles gas was computed from the average chemical analysis to be 1.283 , whereas for air it is 1.40 .

It may be shown, ${ }^{10}$ however, that when $x$ is small, equation (32) is, very nearly, of the more definite form

$$
Y=\psi\left(\frac{x}{\gamma}\right)
$$


and this means that equation (31) may be regarded as a special case of the more general equation

$$
Y=1-1.283\left(0.31+0.35 \beta^{4}\right) \frac{x}{\gamma}
$$

or

$$
Y=1-\left(0.40+0.46 \beta^{4}\right) \frac{x}{\gamma}
$$

applicable to all nearly ideal gases.

In the case of air, with $\gamma=1.40$, the general equation reduces to

$$
Y=1-\left(0.29+0.33 \beta^{4}\right) x
$$

and this equation will be used for finding values of $K$ from our observed values of $C$.

\section{WITTE'S VALUES OF $K$ FOR SMOOTH PIPES}

The experiments now in question, which are only a small part of Witte's extensive researches on nozzles and orifices, were carried out in smooth pipes, and the orifice plates were finished with great care to have the upstream corner of the hole perfectly square and sharp. The results are so important that it is advisable to quote them here and they are given in Table 21, the figures in colums $1,2,4$, and 5 being copied directly from Table 7 of the original paper. ${ }^{11}$

The four pipes used were of approximately $2,4,8$, and 12 inches in diameter, and the 24 orifices tested had the area ratios shown in column 2 of Table 21. Each orifice was tested at various rates of flow, the numbers of separate tests being given in column 4, and the

\begin{tabular}{|c|c|c|c|c|c|c|}
\hline $\begin{array}{l}\text { Diame- } \\
\text { ter of } \\
\text { pipe } \\
\text { [mm] }\end{array}$ & $\begin{array}{l}\text { Area } \\
\text { ratio }\end{array}$ & $\begin{array}{l}\text { Diame- } \\
\text { ter ratio }\end{array}$ & $\begin{array}{c}\text { Number } \\
\text { of tests }\end{array}$ & $\underset{\text { (obs.) }}{K}$ & $\begin{array}{l}0.599+ \\
0.39 \beta \\
=K \\
\text { (calc.) }\end{array}$ & $\begin{array}{c}K \text { (obs.) } \\
-K \text { (calc.) }\end{array}$ \\
\hline 1 & 2 & 3 & 4 & 5 & 6 & g \\
\hline $\begin{array}{r}310 \\
\left(12^{\prime \prime} .2\right)\end{array}$ & $\begin{array}{r}\text { Per cent } \\
9.2 \\
23.4 \\
33.7 \\
46.8 \\
55.0\end{array}$ & $\begin{array}{c}\beta \\
0.303 \\
.484 \\
.580 \\
.684 \\
.742\end{array}$ & $\begin{array}{r}7 \\
12 \\
12 \\
9 \\
6\end{array}$ & $\begin{array}{r}0.602 \\
.621 \\
.642 \\
.685 \\
.717\end{array}$ & $\begin{array}{r}0.602 \\
.620 \\
.643 \\
.684 \\
.717\end{array}$ & $\begin{array}{r}0.000 \\
.001 \\
-.001 \\
.001 \\
.000\end{array}$ \\
\hline $\begin{array}{r}200 \\
\left(7^{\prime \prime} .9\right)\end{array}$ & $\begin{array}{r}5.1 \\
9.9 \\
20.2 \\
30.3 \\
39.7 \\
49.0 \\
49.5 \\
64.2 \\
70.1\end{array}$ & $\begin{array}{r}.226 \\
.315 \\
.450 \\
.550 \\
.630 \\
.700 \\
.703 \\
.801 \\
.837\end{array}$ & $\begin{array}{r}22 \\
25 \\
17 \\
15 \\
7 \\
17 \\
6 \\
30 \\
21\end{array}$ & $\begin{array}{l}.599 \\
.602 \\
.615 \\
.6365 \\
.661 \\
.693 \\
.693 \\
.770 \\
.808\end{array}$ & $\begin{array}{l}.600 \\
.603 \\
.615 \\
.635 \\
.660 \\
.693 \\
.694 \\
.760 \\
.791\end{array}$ & $\begin{array}{r}-.001 \\
-.001 \\
.000 \\
.001 \\
.001 \\
.000 \\
-.001 \\
.010 \\
.017\end{array}$ \\
\hline $\begin{array}{r}100 \\
\left(3^{\prime \prime} .94\right)\end{array}$ & $\begin{array}{l}36.5 \\
56.9 \\
61.0 \\
70.5\end{array}$ & $\begin{array}{l}.604 \\
.754 \\
.781 \\
.840\end{array}$ & $\begin{array}{r}10 \\
5 \\
12 \\
12\end{array}$ & $\begin{array}{l}.651 \\
.726 \\
.749 \\
.812\end{array}$ & $\begin{array}{l}.651 \\
.725 \\
.745 \\
.793\end{array}$ & $\begin{array}{l}.000 \\
.001 \\
.004 \\
.019\end{array}$ \\
\hline $\begin{array}{r}50 \\
\left(1^{\prime \prime} .97\right)\end{array}$ & $\begin{array}{l}17.6 \\
41.0 \\
51.9 \\
60.9 \\
70.7 \\
81.0\end{array}$ & $\begin{array}{l}.420 \\
.640 \\
.720 \\
.780 \\
.841 \\
.900\end{array}$ & $\begin{array}{l}22 \\
13 \\
29 \\
29 \\
26 \\
14\end{array}$ & $\begin{array}{l}.613 \\
.663 \\
.704 \\
.749 \\
.812 \\
.907\end{array}$ & $\begin{array}{l}.611 \\
.665 \\
.704 \\
.744 \\
.794 \\
.855\end{array}$ & $\begin{array}{r}.002 \\
-.002 \\
.000 \\
.005 \\
.018 \\
.052\end{array}$ \\
\hline
\end{tabular}
resulting average values of $K$ in column 5 .

TABLE 21.-Witte's values of $K$ for perfect orifices in smooth pipes

1 See note 5, p. 130. 
If all the measurements were exact, the points obtained by plotting the values of $K$ against any power of the area ratio should evidently lie on some smooth curve; and when the observed values of $K$ are plotted against $\beta^{4}$, or the square of the area ratio, the points for all diameter ratios up to $\beta=0.75$ do lie extremely close to the straight line represented by the equation

$$
K(\text { calc. })=0.599+0.39 \beta^{4}
$$

Values computed from equation (36) are shown in column 6 of the table and the differences, $K$ (obs.) $-K$ (calc.), in column 7 . Up to $\beta=0.75$, the greatest departure of the observed values from the linear equation (36) is one-third per cent, and the average departure is only about 0.1 per cent.

The equation

$$
K=0.598+0.40 \beta^{4}
$$

is about as good as equation (36) for medium values of $\beta$, but the straight line is a little too steep and the coefficient of $\beta^{4}$ is slightly but distinctly too high.

Since the diameter ratios of Witte's orifices did not correspond exactly to those of the orifices used in our experiments, a comparison between the two sets of results requires the use of some sort of interpolation formula, and for this purpose equation (36) will be taken as representing the aggregate of Witte's results, for $\beta \equiv 0.75$, within their experimental accuracy.

\section{COMPARISON OF THE CHICAGO RESULTS FOR AIR WITH WITTE'S RESULTS FOR WATER}

To make one of our values of $C$ comparable with the corresponding value of $K$ obtained by Witte, it has first to be multiplied by $C(1,1) / C(12,6)$ to take account of the difference of tap location; this product has then to be divided by the expansion factor $Y$, so as to give the value of

$$
K=C(12,6) \times \frac{C(1,1)}{C(12,6)} \div Y
$$

The mean values of $C$ from the holder tests, reduced in this manner, are exhibited in Table 22 . Columns 3 and 4 give the mean values of $C$ and $100 x$, found by averaging the separate values in Tables 16 and 17; column 5 gives the factor for change of tap location, from Table 19 ; column 6 gives the value of the expansion factor for the given values of $\beta$ and $x$, computed from equation (35); column 7 gives the resulting value of $K$ for taps distant $D / 24$ from the orifice plate; and column 8 gives the value of $K$ from equation (36), which represents Witte's results for taps in the corner. 
TABLE 22.-Orifice coefficients measured by the holder, compared with Witte's results for water

\begin{tabular}{|c|c|c|c|c|c|c|c|}
\hline $\begin{array}{l}\text { Area } \\
\text { ratio }\end{array}$ & $\begin{array}{l}\text { Number } \\
\text { of tests } \\
\text { averaged }\end{array}$ & $C(12,6)$ & $100 x$ & $\frac{C(1,1)}{C(12,6)}$ & $Y$ & $\begin{array}{c}K \\
\text { (obs.) }\end{array}$ & $\begin{array}{c}K \\
\text { Witte } \\
\text { equ. }(36)\end{array}$ \\
\hline 1 & 2 & 3 & 4 & 5 & 6 & 7 & 8 \\
\hline $\begin{array}{c}\text { Per cent } \\
5 \\
10 \\
20 \\
30\end{array}$ & $\begin{array}{r}6 \\
2 \\
13 \\
8\end{array}$ & $\begin{array}{l}0.594 \\
.597 \\
.6085 \\
.6285\end{array}$ & $\begin{array}{l}2.00 \\
0.99 \\
3.05 \\
3.10\end{array}$ & $\begin{array}{l}1.001 \\
1.001 \\
1.000 \\
0.999\end{array}$ & $\begin{array}{r}0.9942 \\
.9971 \\
.9908 \\
.9901\end{array}$ & $\begin{array}{r}0.598 \\
.599 \\
.614 \\
.634\end{array}$ & $\begin{array}{r}0.600 \\
.603 \\
.615 \\
.634\end{array}$ \\
\hline
\end{tabular}

Our values of $C$, and therefore of $K$, are much less reliable for the two smaller than for the two larger orifices; for the holder was better adapted to testing the 20 and 30 per cent orifices and there were more tests. The values of $K$, computed in accordance with equation (38) from the mean values of $C$, are thus intrinsically more probable than for the two smaller orifices, and they are in very good agreement with Witte's values as represented by equation (36).

The values of $C$ obtained from the comparison runs in which the Venturi was used as the standard have also been reduced in the manner described above, and the resulting values of $K$ for the 10 to 65 per cent orifices are exhibited in Table 23.

TABLE 23.-Orifice coefficients measured by the Venturi meter compared with Witte's results for water

\begin{tabular}{|c|c|c|c|c|c|c|c|}
\hline $\begin{array}{l}\text { Area } \\
\text { ratio }\end{array}$ & $\begin{array}{l}\text { Number } \\
\text { of tests } \\
\text { averaged }\end{array}$ & $C(12,6)$ & $100 x$ & $K$ (obs.) & $\begin{array}{l}K \text { (calc.) } \\
\text { by equa- } \\
\text { tion }(36)\end{array}$ & $\begin{array}{l}K \text { (calc.) } \\
\text { by equa- } \\
\text { tion (39) }\end{array}$ & $\begin{array}{l}K \text { (calc.) } \\
\text { by equa- } \\
\text { tion }(40)\end{array}$ \\
\hline 1 & 2 & 3 & 4 & j & 6 & 7 & 8 \\
\hline $\begin{array}{c}\text { Per cent } \\
10 \\
20 \\
30 \\
35 \\
40\end{array}$ & $\begin{array}{l} \\
5 \\
3 \\
3 \\
1 \\
2\end{array}$ & $\begin{array}{c}0.5926 \\
.6060 \\
.6293 \\
.640 \\
.669\end{array}$ & $\begin{array}{l}5.62 \\
3.67 \\
2.28 \\
2.87 \\
1.12\end{array}$ & $\begin{array}{r}0.603 \\
.613 \\
.633 \\
.645 \\
.670\end{array}$ & $\begin{array}{r}0.603 \\
.615 \\
.634 \\
.647 \\
.661\end{array}$ & $\begin{array}{r}0.601 \\
.613 \\
.634 \\
.647 \\
.663\end{array}$ & $\begin{array}{l}0.602 \\
.614 \\
.634 \\
.647 \\
.662\end{array}$ \\
\hline $\begin{array}{l}45 \\
50 \\
55 \\
60 \\
65\end{array}$ & $\begin{array}{l}2 \\
2 \\
2 \\
1 \\
1\end{array}$ & $\begin{array}{l}.650 \\
.704 \\
.7285 \\
.760 \\
.801\end{array}$ & $\begin{array}{l}1.20 \\
.86 \\
.68 \\
.79 \\
.66\end{array}$ & $\begin{array}{l}.680 \\
.700 \\
.721 \\
.748 \\
.783\end{array}$ & $\begin{array}{l}.678 \\
.697 \\
.717 \\
.737 \\
.764\end{array}$ & $\begin{array}{l}.680 \\
.700 \\
.721 \\
.745 \\
.770\end{array}$ & $\begin{array}{r}.679 \\
.699 \\
.719 \\
.742 \\
.767\end{array}$ \\
\hline
\end{tabular}

Columns 3 and 4 contain the means of the separate values of $C$ and of $100 x$ in columns 3 and 4 of Table 18; and the values of $K$ deduced from these means are given in column 5 . Column 6 gives the values of $K$ computed from equation (36) or

$$
K=0.599+0.39 \beta^{4}
$$

which represents Witte's results up to $\beta=0.75$; and columns 7 and 8 give the corresponding values from the slightly modified equations

and

$$
K=0.597+0.41 \beta^{4}
$$

$$
K=0.598+0.40 \beta^{4}
$$


Our mean values of $K$ from both Table 22 and Table 23 are plotted against values of $\beta^{4}$ in Figure 8 , in which the two straight lines represent equations (36) and (39).

Table 23 and Figure 8 do not include values of $K$ for the 70,75, and 80 per cent orifices, although observed values of $C$ are given in Table 18. Our failure to get satisfactory observations of the longitudinal



FIGURE 8.-Results of orifice coefficient determinations by Chicago tests compared with the line $W$, representing the results of Witte's tests

distribution of pressure with these large orifices made it impossible to extend Table 19 beyond the 65 per cent orifice.

\section{CONCLUSIONS FROM THE FOREGOING COMPARISON}

Examination of Tables 21, 22, and 23 and Figure 8 leads to the following conclusions:

(a) The values of $K$, deduced from our experiments with the holder by utilizing the observations on the longitudinal distribution of 
pressure and the information regarding the expansion factor furnished by the Los Angeles experiments with natural gas, agree with the values of $K$ from Witte's experiments with water, within the accidental errors of experiment. The agreement is closest for our 20 and 30 per cent orifices, and these are the ones on which our tests were most numerous and most reliable. This comparison does not go beyond an area ratio of 30 per cent, for which $\beta=0.548$.

(b) When the tests on the larger orifices, with the Venturi as the standard, are also taken into account, it appears that, up to and including the 55 per cent orifice, equation (39) reproduces our results somewhat better than equation (36); or, graphically, the best straight line through our points is a little steeper than the best line through Witte's points.

(c) The value of $K$ for our 40 per cent orifice is based on the mean of two rather discordant values of $C$ (see Table 18), of which at least one must have been affected by some unusually large error. Omitting this value, we have for the remaining 8 orifices, up to and including the 55 per cent orifice, 4 values of $K$ from experiments with the holder and 7 values from comparisons with the Venturi. There are also the 17 values given in Table 21 from Witte's experiments with area ratios up to 56.9 per cent. The mean equation (40) reproduces all these 28 values of $K$ with an extreme departure of 0.5 per cent, for one of Witte's orifices and one of ours, and an average departure of somewhat less than 0.2 per cent.

(d) As the area ratio increases beyond about 57 per cent $(\sqrt{0.57}=$ $0.75+)$, the value of $K$ increases faster than before and the simple linear relations (36) and (39) no longer hold. This is evident from the data in Tables 21 and 23.

\section{REMARKS}

The difference between the lines $W$ and $C$ of Figure 8 appears to be significant and not merely accidental, but we are not, at present, able to interpret this difference with certainty.

Increasing the roughness of the wall of the pipe increases the slope of the line, and it is possible that our 24-inch pipe was rougher than the pipes used by Witte, to a sufficient degree to account for the difference mentioned; but this interpretation does not seem satisfactory. For aside from the fact that our pipe was actually very smooth, increasing the roughness of the pipe not only makes the line $K=f\left(\beta^{4}\right)$ steeper, but shifts it bodily upward, whereas the lines $W$ and $C$ of Figure 8 cross at the point where our observations are most trustworthy.

We are more.inclined to attribute the difference of slopes to the different locations of the pressure connections, for the following reasons:

In an earlier paper, ${ }^{12}$ Witte gives the results of measurements of the rise of pressure from the upstream minimum to the plate, and of the fall from the plate to the downstream minimum. The values are given only in the form of small-scale curves, but we can get from them approximate values which correspond to a continuation, right up to the faces of the plate, of our observations on the longitudinal distribution of pressure which stopped 1 inch away. 
On the downstream side, the points thus obtained lie on entirely natural extrapolations from our series of observed points; but on the upstream side there is a systematic difference. For the small diameter ratios, Witte's points are lower than would be expected from a tentative extrapolation of our curves, whereas at the large diameter ratios they are much higher. The indications are that shifting the pressure taps from our last position, 1 inch from the plate, to Witte's position, in the corner, will decrease the observed differential, slightly for small area ratios but increase it considerably for large ratios.

The values of $C$ or $K$ computed from the observed differentials will, of course, be affected in the opposite sense; and this is the sense in which Witte's values of $K$, represented by line $W$ in Figure 8, differ from ours, which are represented by line $C$.

It is not possible to pursue this analysis quantitatively, without further detailed investigation of the variations of pressure close to the plate, but it is evident that such investigations are highly desirable.

\section{GRAPHICAL REPRESENTATION OF TABLES 16, 17, AND 18}

Tables 22 and 23 and Figure 8 deal only with mean values, and to give an idea of the consistency of our separate determinations of the discharge coefficients with one another and with the results of the Los Angeles experiments, embodied in equation (35), Figure 9 has been prepared.

The ordinates are values of $C \equiv C(12,6)$, observed with the pressure taps 12 inches upstream and 6 inches downstream; and the abscissas are the values of $100 x$ at which the observations were made.

Each point represents a single value of $C$; the points surrounded by triangles are values obtained in the tests with the holder, and their coordinates are taken from Tables 16 and 17 ; and the points in the circles are values from the comparison runs against the Venturi, iheir coordinates being taken from Table 18. The points for each orifice are grouped, more or less closely, about a straight line; and the number at the right-hand end of the line is the area ratio of the orifice, in per cent.

The intercept and slope of the line for each orifice were determined as follows : It was first assumed that if the taps had been 1 inch from the plate, the value of

$$
K \equiv K(1,1)=\text { limit of } C(1,1) \text { as } x \doteq 0
$$

would have satisfied equation (39), represented by line $C$ in Figure 8; and the value of $K(1,1)$ was computed for the given value of $\beta$, from equation (39).

The corresponding value of

$$
K(12,6)=\text { limit of } C(12,6) \text { as } x \doteq 0
$$

was then found from the relation

$$
K(12,6)=K(1,1) \div \frac{C(1,1)}{C(12,6)}
$$


by taking the value of $C(1,1) / C(12,6)$ from the last column of Table (19). This gave the required intercept of the straight line on the $C$ axis.

The expansion factor at $x=0.1$ was next computed from (35), and when multiplied by the value of $K(12,6)$ already found, this gave the ordinate of the line at $x=0.1$. The two points thus determined, for $x=0$ and $x=0.1$, were then plotted and the straight line was drawn through them.

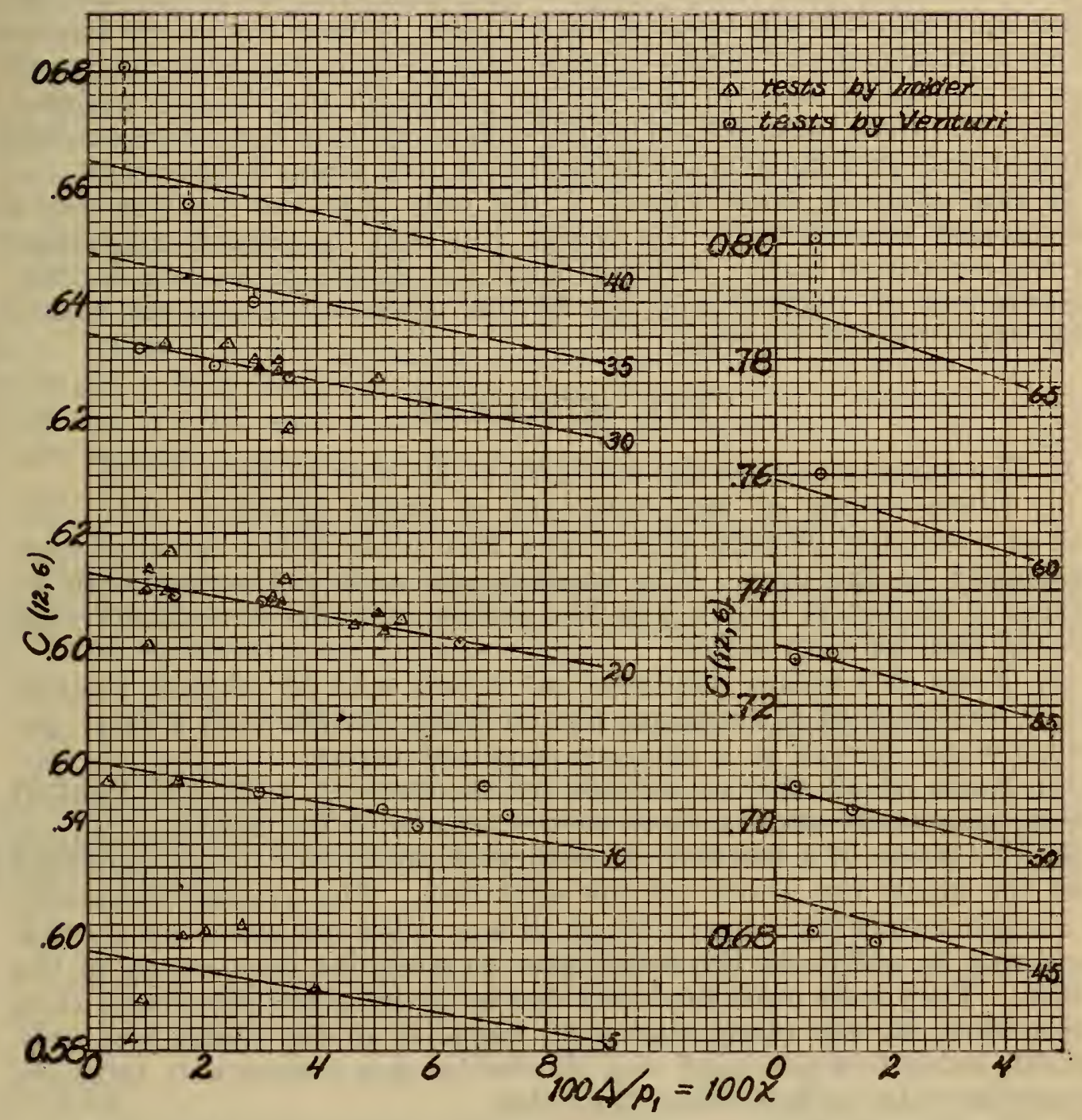

Figure 9.-Actual test results plotted from Tables 16, 17, and 18

The numbers at the right of the slanting lines are values of $100 \beta^{2}$.

For the 5 per cent orifice ( $d=5.2$ inches), the rate of flow attainable was limited by the maximum pressure the booster could give, and the greatest differential that could be reached at the Venturi was less than 0.3 inch. Since this was too low for accurate measurement, the Venturi tests were worthless and are not shown. The rates of flow were also too low to be measured satisfactorily with so large a holder, and the points from the holder runs are considerably scattered.

For the 10,20 , and 30 per cent orifices, there are points representing the results of both kinds of test. The higher rates of flow were more favorable to accuracy, and the points are less scattered than for 
the 5 per cent orifice. Two of the Venturi points for the 10 per cent orifice are rather far out of line with the others; but the greatest differential at the Venturi was less than 1.7 inches, and the greatest departure of any of the points from the straight line corresponds to an error of only about 0.04 inch in reading this differential.

Aside from these two points, the Venturi and holder points are mixed indiscriminately, for all three orifices, and the use of the Venturi as a secondary standard, after calibration by the holder, is justified.

For the larger area ratios, there are no tests with the holder and, at most, only two Venturi tests for each orifice. One of the values for the 40 per cent orifice is evidently considerably in error; but with the exception of this point, none of the Venturi points for the 20 to 60 per cent orifices, inclusive, is more than 0.6 per cent away from the corresponding straight line, and the average departure is only about 0.2 per cent.

It thus appears, from Figure 9, not only that the Venturi was a satisfactory substitute for the holder, but that the general expression for the expansion factor, deduced from the results of the Los Angeles experiments on natural gas, did fit our observations on air within their experimental accuracy.

\section{SUMMARY}

1. The experiments on the metering of air were of three kinds:

(a) Observations of the variation of static pressure along the wall of a smooth, 24-inch pipe near a thin-plate orifice installed concentrically in the pipe. The experiments were performed with 14 orifices of diameters from 5.2 to 20.6 inches, and with several different rates of flow for each orifice.

(b) Tests of a rotary displacement meter, a 24 by 12 inch Venturi meter, and four of the orifices, the air being drawn from a large gas holder which served as a primary standard meter.

(c) Tests of all the 14 orifices by comparison with the Venturi meter, previously standardized in the tests with the holder.

2 . The mean of 8 tests of the rotary displacement meter indicated that the meter ran about 0.6 per cent fast. The average departure of a single result from the mean of all was \pm 0.4 per cent, but there is no reason to attribute the departures to irregular functioning of the meter. They were more probably due to errors in the observations on the holder; for the rated maximum capacity of the meter was only 200,000 cubic feet per hour, and the holder was undesirably large for measuring rates of flow lower than this.

3 . The results of the comparisons of the Venturi with the holder, at rates of flow between 300,000 and 600,000 cubic feet per hour, indicated that within this range, a determination of rate of flow from observations on the rate of fall of the holder which appeared intrinsically satisfactory, was usually accurate to about. \pm 0.3 per cent. 'This corresponded to an accuracy of somewhat better than \pm 2 degrees $\mathrm{F}$. in the temperature, but in reality the limit of accuracy was set by errors in measuring the height rather than the temperature.

4. The results of the comparisons of the orifices with both the holder and the Venturi have been expressed as values of the discharge coefficient $C$, defined by the equation

$$
M=C A \sqrt{2\left(p_{1}-p_{2}\right) \rho_{1}}
$$


in which $M \mathrm{lbs}$./sec. is the rate of flow as measured by the fall of the holder or by the standardized Venturi; $A$ square feet is the area of the orifice; $p_{1}$ and $p_{2}$ poundals per square foot are the pressures observed at the upstream and downstream pressure taps; and $\rho_{1} \mathrm{lbs} . / \mathrm{ft} .{ }^{3}$ is the density of the air at the pressure $p_{1}$ and at the upstream temperature.

By utilizing the results of the experiments of group $A$ and of later experiments on natural gas, the values of $C$ have been so reduced as to be comparable with the values for water obtained by $\mathrm{R}$. Witte with apparatus that was very nearly, though not exactly, geometrically similar to ours. The agreement of the two sets of values is very close in the region where our own values are most reliable.

There appear to be small systematic differences, which increase to about 0.7 per cent when the ratio of orifice to pipe diameter is as large as 0.75 , but they can not be interpreted or explained with any confidence until the variations of pressure in the immediate vicinity of the orifice plate have been further investigated.

If we let $\beta \equiv d / D$ denote the ratio of the diameter of the orifice to that of the pipe, and $x \equiv\left(p_{1}-p_{2}\right) / p_{1}$ denote the differential expressed as a fraction of the upstream absolute pressure; and if the pressure taps are 1 inch from the orifice plate, our results for diameter ratios between $\beta=0.3$ and $\beta=0.77$ may all be represented, within their experimental accuracy, by the empirical equation

$$
C=\left(0.597+0.41 \beta^{4}\right)\left[1-\left(0.29+0.33 \beta^{4}\right) x\right]
$$

The experiments did not go beyond $x=0.08$, but the equation is probably valid for considerable higher values of $x$. For higher values of $\beta$, the equation gives too low values.

\section{Note A.-THE ADIABATIC DISCHARGE COEFFICIENT}

The "adiabatic discharge coefficient" $C_{a}$ results from computing the theoretical mass flow on the assumptions that the fluid is an ideal gas and that the expansion from $p_{1}$ to $p_{2}$ is isentropic. It is defined by the equation

in which

$$
M=C_{a} \frac{\pi}{4} d^{2}\left[\frac{2 \gamma}{\gamma-1} p_{1} \rho_{1} \frac{\left(\frac{p_{2}}{p_{1}}\right)^{\frac{2}{\gamma}}-\left(\frac{p_{2}}{p_{1}}\right)^{\frac{\gamma+1}{\gamma}}}{1-\beta^{4}\left(\frac{p_{2}}{p_{1}}\right)^{\frac{2}{\gamma}}}\right]^{\frac{1}{2}}
$$

$M=$ the mass flow;

$d=$ the diameter of the Venturi throat;

- $p_{1}, p_{2}=$ the observed upstream and downstream pressures;

$\rho_{1}=$ the upstream density;

$\beta=d / D=$ the diameter ratio; and

$\gamma=C_{p} / C_{v}=$ the specific heat ratio.

The hydraulic discharge coefficient $C$, based on the upstream density and with the approach factor included, is defined by the equation

$$
M=C \frac{\pi}{4} a^{2} \sqrt{2 \rho_{1}\left(p_{1}-p_{2}\right)}
$$

$60869-31-10$ 
By equating these two expressions for $M$ we get the relation

$$
\frac{C_{a}}{C}=\left\{\frac{\gamma-1}{\gamma} \cdot \frac{\left(1-\frac{p_{2}}{p_{1}}\right)\left[1-\beta^{4}\left(\frac{p_{2}}{p_{1}}\right)^{\frac{2}{\gamma}}\right.}{\left(\frac{p_{2}}{p_{1}}\right)^{\frac{2}{\gamma}}-\left(\frac{p_{2}}{p_{1}}\right)^{\frac{\gamma+1}{\gamma}}}\right\}^{\frac{1}{2}}
$$

Or if we let $p_{2} / p_{1}=r$ and set $\gamma=1.4$ as for air, we have

$$
\frac{C_{a}}{C}=\left[\frac{2(1-r)\left(1-\beta^{4} r^{\frac{10}{7}}\right)}{7\left(r^{\frac{10}{7}}-r^{\frac{12}{7}}\right)}\right]^{\frac{1}{2}}
$$

or equation (15) of Section X, 6 .

\section{Note B.-THE REYNOLDS NUMBER}

In the case of a stream of fluid along a round pipe, the Reynolds number is usually defined as the value of the expression

$$
R_{D}=\frac{D S_{1} \rho_{1}}{\mu}
$$

in which $D=$ the diameter of the pipe; $S_{1}=$ the mean linear speed along the pipe; $\rho_{1}=$ the density of the fluid; and $\mu=i$ ts viscosity. All the quantities are understood to be measured by some system of normal units, such as the British absolute or the cgs., and since the expression is of zero dimensions, its numerical value is the same in all such systems.

The mean speed has to be determined indirectly from the rate of discharge $M$, by means of the equation

$$
M=\frac{\pi}{4} D^{2} S_{1} \rho_{1}
$$

and equation (1) might be written in the form

$$
R_{D}=\frac{4 M}{\pi D_{\mu}}
$$

but the traditional form equation (1) is retained here as more familiar.

As is well known, the effects of viscosity on the nature of the fluid motion depend on the value of $R_{D}$, which serves as a criterion, or an independent variable, in discussing these effects on skin friction, etc.

If a Venturi of throat diameter $d=\beta D$ is included in the pipe line, its discharge coefficient depends on the motion in the approaching stream and therefore on the value of $R_{D}$; but it is more natural to adopt as the independent variable or Reynolds number, the analogous expression

$$
R_{d}=\frac{d S_{2} \rho_{2}}{\mu}
$$

in which $\rho_{2}$ and $S_{2}$ are the density and mean speed at the throat; and this second form of Reynolds number is physically more signifi- 
cant than the first, because the nature of the motion through the throat is more influenced by the size of the throat than by the size of the pipe.

Equation (4) may also be written in the form

$$
R_{d}=\frac{4 M}{\pi d \mu}
$$

corresponding with equation (3); and since $M$ is the same in both equations, and the viscosity is nearly the same at the throat as in the approach pipe, comparison of equation (3) with equation (5) gives the approximate relation

$$
R_{D}=\beta R_{d}
$$

and either form of the Reynolds number may be found from the other. Similarly, for an orifice of diameter $d$ installed in a pipe of diameter $D$, the nature of the motion and the value of the discharge coefficient, in so far as they are influenced by the viscosity of the fluid, may be regarded as dependent on either $R_{D}$ or $R_{d}=R_{D} / \beta$.

In any event, and whether it is an orifice, a Venturi, or a straight pipe that is under consideration, the effects of viscosity on the motion of the fluid become negligible when the viscosity itself is sufficiently low; and since these effects are not determined merely by the value of $\mu$, but by the value of the Reynolds number as a whole, they become insignificant when either $R_{D}$ or $R_{d}$ is made very large.

For further information on the experimental side of this subject the reader may be referred to papers by J. L. Hodgson, ${ }^{13} \mathrm{R}$. Witte, ${ }^{14}$ and F. C. Johansen. ${ }^{15}$

Washington, May 13, 1931.

13 Inst. Civ. Eng., Selected Engineering Papers, No. 31, 1925.

14 See footnote 5, p. 130 and 12, p. 139.

is Proc. Roy, Soc. London, A 126, p. 231, 1929. 